\title{
Fase preanalítica: punto crítico en las pruebas de diagnóstico hematológico
}

\author{
Preanalytic phase: a critical point in hematological diagnosis tests
}

\author{
Natalia M. Guevara-Arismendy $M S c^{1}$, \\ Verónica J. Tangarife-Castaño MSc²
}

Resumen: la fase preanalítica es un componente importante de los procesos operacionales realizados en los laboratorios clínicos, en la que se desarrollan diversos procedimientos que pueden afectar el resultado de un examen de sangre, tejidos o fluidos corporales de un paciente. Esta fase va desde la orden médica hasta el inicio del procesamiento de la muestra (fase analítica). Específicamente, en el diagnóstico hematológico los exámenes de laboratorio son la principal fuente de información para la toma de decisiones médicas relacionadas con el tratamiento y el seguimiento de los pacientes; por tal razón, el control de todos los aspectos involucrados en la fase preanalítica debe ser una prioridad en todos los laboratorios clínicos. En esta revisión se presentan los principales aspectos preanalíticos de las pruebas más comunes en el diagnóstico hematológico, correspondientes a las áreas de coagulación básica y especializada, hematología general y especializada, citometría de flujo, citogenética, biología molecular, entre otras de interés.

Palabras clave: servicios de laboratorio clínico, hematología, fase preanalítica, mejoramiento de la calidad.

Abstract: The preanalytic phase is an important component of operational processes performed in clinical laboratories, which includes various processes that can affect the outcome of a patient's blood, tissue and fluid examination, ranging from the

${ }^{1}$ Microbióloga y Bioanalista, MSc en Microbiología y Bioanálisis con énfasis en Hematología. Bacterióloga, Laboratorio Clínico Hematológico. Medellín, Colombia. Correo electrónico: nguevara@hematologico.com 2 Microbióloga y Bioanalista, MSc en Ciencias Básicas Biomédicas con énfasis en Microbiología y Parasitología. Coordinadora Científica, Editora Médica Colombiana. Medellín, Colombia.

Conflicto de intereses: las autoras declaran que no tienen conflicto de intereses

Medicina \& Laboratorio 2016; 22: 411-446

Módulo 1 (La Clínica y el Laboratorio), número 118. Editora Médica Colombiana S.A. $2016^{\circ}$

Recibido el 15 de septiembre de 2016; aceptado el 04 de octubre de 2016 
medical order until the beginning of the processing of the sample (analytical phase). Specifically, laboratory tests are the main source of information in haematological diagnosis for medical decisions related to the treatment and follow-up of patients. For this reason, control of all aspects involved in the preanalytic phase should be a priority in all clinical laboratories. In this review, we present the main preanalytical aspects of the most common tests in the hematological diagnosis, corresponding to the areas of basic and specialized coagulation, general and specialized hematology, flow cytometry, cytogenetics, and molecular biology, among others of interest.

Key words: Clinical laboratory service, hematology, preanalytical phase, quality improvement.

Guevara-Arismendy NM, Tangarife-Castaño VJ. Fase preanalítica: punto crítico en las pruebas de diagnóstico hematológico. Medicina \& Laboratorio 2016; 22: 411-446.

L as pruebas de laboratorio proveen hasta el $80 \%$ de la información que se tiene en cuenta para el abordaje clínico y terapéutico de los pacientes [1], por lo cual el laboratorio clínico, como una rama del área de la salud especializada en el diagnóstico [2], es un componente esencial en la práctica médica. En este sentido, los laboratorios clínicos ofrecen información valiosa para aclarar una sospecha diagnóstica, realizar el seguimiento de los pacientes, detectar complicaciones en múltiples enfermedades e identificar eventos de interés en salud pública [2,3]. Es por ello que los profesionales de laboratorio clínico deben desarrollar todos los procesos con altos estándares de calidad, de modo que se disminuyan los errores que puedan afectar la determinación o cuantificación de analitos y que, a su vez, influyan en el manejo clínico de los pacientes [4].

En el área de hematología el diagnóstico, el seguimiento y la respuesta de los pacientes es determinado a partir de la integración de los exámenes de laboratorio. Este artículo de revisión tiene como propósito revisar los aspectos preanalíticos de las principales pruebas de interés en el diagnóstico hematológico. Para ello, se presentarán las consideraciones generales, el impacto de los errores y las condiciones específicas de la fase preanalítica para los exámenes hematológicos, entre los que se incluyen los de coagulación básica y especializada, hematología general y especializada, citometría de flujo, citogenética, biología molecular y otras pruebas de interés hematológico.

\section{Fase preanalítica: generalidades}

En términos generales, la ejecución de los exámenes de laboratorio se realiza en tres fases: preanalítica, analítica y posanalítica. La fase preanalítica corresponde a los procesos que comienzan a partir de la orden médica de los exámenes, la preparación y la identificación del paciente, la toma de las muestras, el almace- 
namiento y el transporte hasta el laboratorio; y termina cuando comienza la fase analítica, en la cual se detecta el analito de interés, y que continúa con la fase posanalítica, correspondiente a los procesos que siguen al análisis, en donde se incluye la revisión de los resultados, el almacenamiento de material, el descarte y tratamiento de residuos, la generación de resultados, la autorización para su entrega, el informe de resultados y la retención de los mismos [5,6]. Algunos autores hacen referencia también a la fase pre-preanalítica y pos-posanalítica estrechamente relacionadas con el quehacer del médico.

En la actualidad, la mayor frecuencia de errores en los laboratorios clínicos ocurre durante la fase preanalítica [7], ya que es la fase menos automatizada, con participación de personal de la salud de diversas áreas que, si no es consciente de los requisitos mínimos que deben tener las muestras, puede influir negativamente en la toma de estas. Además, en la fase analítica se han establecido procedimientos cada vez más automatizados que facilitan la disminución de errores $[1,8]$ y se cuenta con controles de calidad tanto internos como externos [9], entre otros mecanismos de control y de mejora continua; finalmente, la fase posanalítica depende del éxito de las dos anteriores. Si bien la calidad de los métodos analíticos que se emplean es decisiva, no se debe negar el gran impacto que representa la correcta preparación del paciente, los cuidados para la toma de la muestra, el análisis y la validación de los resultados [2].

Entre los procesos que conforman la fase preanalítica se destacan la solicitud del análisis (orden médica), la preparación del paciente, la toma de la muestra, el transporte, la conservación y el preprocesamiento de la muestra previa a su análisis [10] (véase figura 1); de allí que esta fase se considere un punto crítico para la correcta ejecución de los demás procesos en el laboratorio clínico [8]. De esta manera, resulta esencial el control de múltiples factores, la identificación de errores y el establecimiento de acciones correctivas que lleven a disminuir las fuentes de error a través de la ejecución de procedimientos estandarizados durante todas las fases [3].

\section{Caracterización de los errores durante la fase preanalítica}

En la fase preanalítica es donde se cometen la mayoría de errores en los laboratorios clínicos $[7,9,11,12]$, principalmente durante la ejecución de los procedimientos manuales [7]. En esta fase se han reportado frecuencias de error que incluso superan el $60 \%$ respecto al total de errores alcanzados en los laboratorios clínicos $[4,10,12]$.

Dichos errores son de naturaleza heterogénea y se pueden originar por una deficiente formación del personal, la falta de conocimiento sobre las condiciones adecuadas para tomar una muestra y la ejecución de los demás procesos de la fase preanalítica [7], así como a un inadecuado cumplimiento de las condiciones 


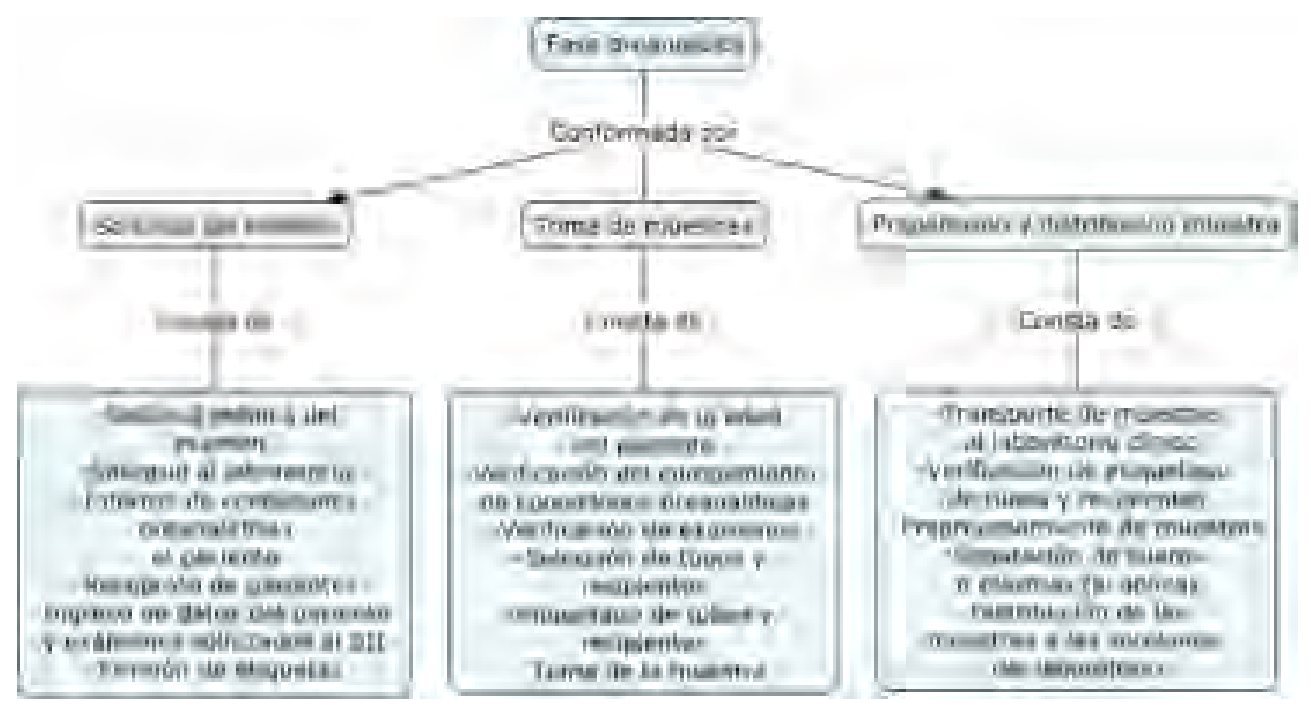

Figura 1. Principales procesos de la fase preanalítica. SIL: Sistema de Información del Laboratorio.

preanalíticas por parte del paciente, lo cual puede darse porque no fue informado correctamente o porque, por desconocimiento del efecto que puede tener el incumplimiento de dichos requerimientos sobre los resultados obtenidos, hace caso omiso y no lo informa al personal del laboratorio. En un estudio mexicano se encontró que el $77,2 \%$ de los pacientes no recibieron la orientación adecuada previa a la toma de muestra, por lo que no se prepararon adecuadamente para dicha actividad [3]. Esto refleja que el informe claro y oportuno de las condiciones que debe cumplir el paciente para la toma de las muestras es un procedimiento esencial durante la fase preanalítica y que su correcto control contribuirá positivamente a la calidad de la muestra obtenida.

Una de las condiciones preanalíticas exigidas en la mayoría de las pruebas de laboratorio y que resulta clave para la obtención de un resultado correcto es el tiempo de ayuno previo a la toma de la muestra. Con frecuencia se recomienda un ayuno entre las 8 y 12 horas; sin embargo, el tiempo de ayuno ideal debe ser de 12 horas, ya que el incremento de los triglicéridos en la sangre después del consumo de los alimentos puede persistir incluso durante nueve horas [3]. Esto resulta esencial no solo para la determinación de los triglicéridos y el perfil lipídico, sino para la determinación de analitos en los cuales la turbidez de la muestra generada por los triglicéridos puede alterar las determinaciones foto-ópticas en los instrumentos de medida; por ejemplo, esto puede generar un falso incremento de los niveles de hemoglobina [13]. En un estudio realizado en una población española se encontró que solo un $21,5 \%$ de los pacientes cumplió con el ayuno de 12 horas debido en gran parte al desconocimiento de este requerimiento o, como se indicó previamente, no lo consideraron importante [14]. 
Otros errores que se presentan con frecuencia durante la fase preanalítica en los laboratorios clínicos es la incorrecta identificación de los pacientes o de las muestras, la inadecuada toma de las muestras y la insuficiente calidad/cantidad de estas (véase tabla 1) $[3,4,7,10,12,15,16]$.

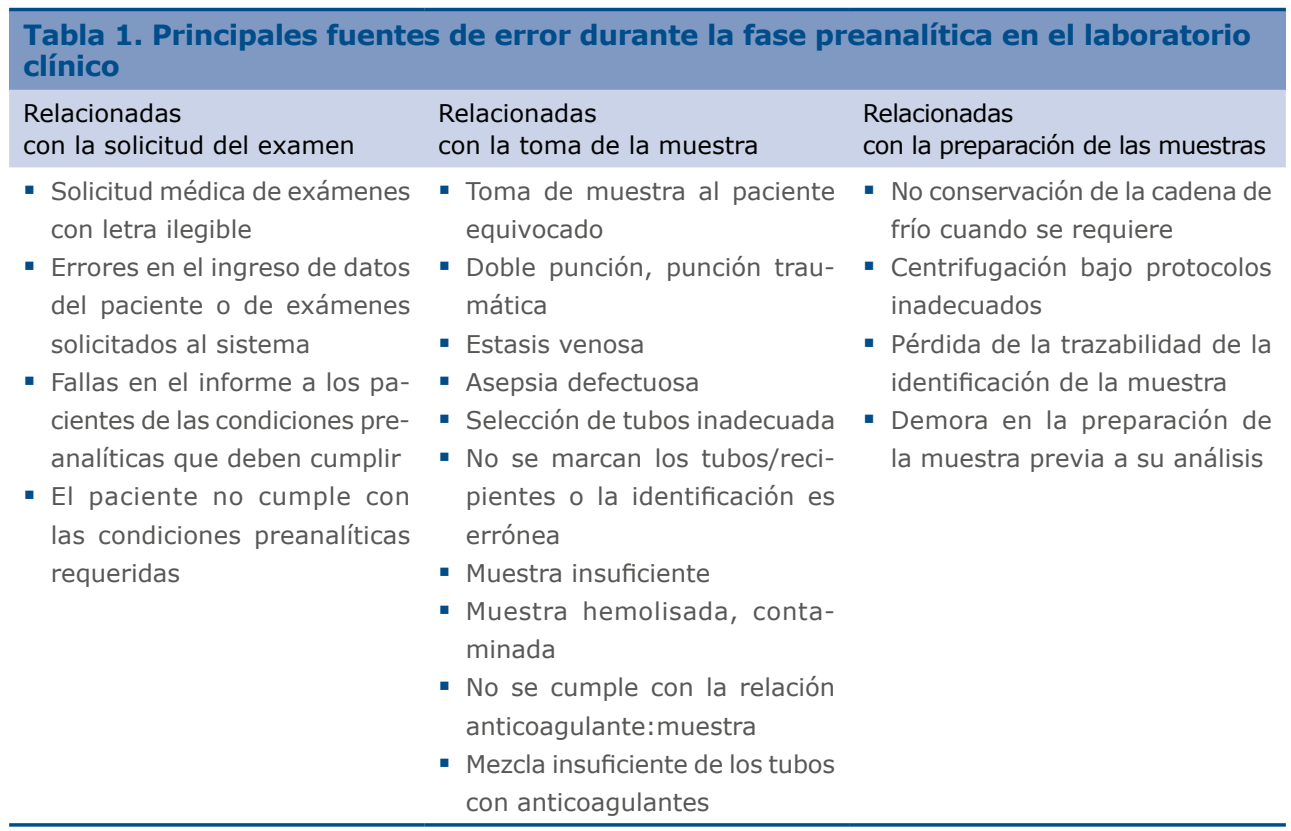

También se debe considerar que la presencia de interferencias en la muestra y algunas condiciones de los pacientes, susceptibles o no de modificación, pueden afectar la exactitud de los resultados y, por lo tanto, su interpretación y aplicación clínica. Los factores que no se pueden modificar, como el sexo, la edad y la raza, se deben tener en cuenta cuando se establecen los intervalos biológicos de referencia y para el análisis de los resultados, mientras que otros factores modificables, como el tabaquismo, el alcoholismo, el ejercicio, el estrés, la ingesta de medicamentos y otras actividades, se deben tener presentes cuando se le explican al paciente las condiciones que debe cumplir para la toma de la muestra para garantizar la confiabilidad de los resultados del laboratorio $[2,17,18]$. Así mismo, se pueden presentar errores en la solicitud de los exámenes cuando el médico ordena un examen de poca utilidad para el diagnóstico o el seguimiento de la enfermedad de interés $[16,19]$; no obstante, esta fuente de error no es objeto de la presente revisión.

Por otra parte, se presenta un mayor control sobre la fase preanalítica cuando la toma de las muestras está a cargo de los bacteriólogos y microbiólogos (o sus homólogos internacionales), tal como lo demuestran los resultados de una encuesta aplicada a trabajadores de hospitales y laboratorios, en los cuales se 
evidencia que el personal de laboratorio posee mejores prácticas para la toma de muestras que los demás trabajadores de los hospitales que participan en dicho proceso, lo cual puede influir en el número de muestras que se rechazan por fallas en la identificación del paciente o de las muestras y la calidad de estas [20]. Otros estudios reflejan que el principal error en la fase preanalítica es la toma de la muestra con un anticoagulante erróneo o una cantidad insuficiente de la muestra (50,9\% de los errores técnicos detectados), debido al desconocimiento del personal que participa en dicho proceso [21]. Lo anterior evidencia la necesidad de establecer una comunicación continua y apropiada entre los profesionales del laboratorio y los demás profesionales del área de la salud que participan en el proceso $[10,20,21]$.

\section{Consecuencias derivadas de errores cometidos durante la fase preanalítica}

Las consecuencias de los errores durante la fase preanalítica son diversas y pueden afectar el manejo clínico de los pacientes, o pasar inadvertidas. Cuando los errores que se cometen durante la fase preanalítica se identifican inmediatamente o durante la ejecución de los procesos posteriores y se llevan a cabo las acciones correctivas respectivas, se disminuye la posibilidad de generar un evento adverso para el paciente. Otros errores no tienen un impacto significativo en el manejo médico de los pacientes $[9,22]$; sin embargo, cuando se emiten resultados erróneos podría llevar a intervenciones diagnósticas y terapéuticas inadecuadas, con repercusiones sobre el estado de salud del paciente y su pronóstico [7].

Estudios reflejan que el $24,4 \%$ de los errores de laboratorio tienen un impacto negativo sobre el cuidado de los pacientes, con consecuencias tan graves como la admisión inadecuada a la unidad de cuidados intensivos y transfusiones innecesarias [4]; situaciones que habrían sido prevenibles en caso de detectar el error a tiempo. Además, las fallas en la toma de la muestra pueden conducir a situaciones menos drásticas como la repetición de la toma de muestra, que en ocasiones requiere que el paciente acuda de nuevo al laboratorio clínico.

Otras fallas presentadas durante los procesos de venopunción se relacionan con la formación de equimosis, hematomas y otros eventos adversos que se pueden prevenir al realizar una adecuada identificación del sitio de punción y la selección del calibre de aguja según el diámetro de la vena. Si bien estos inconvenientes no representan un riesgo para el estado de salud del paciente se deben evitar al máximo, lo cual se logra a partir del entrenamiento de todo el personal del área de la salud que participe en la toma de la muestra y de la colaboración del paciente para llevar a cabo dicho procedimiento sin percances $[23,24]$. 


\section{Recomendaciones generales para la ejecución de procesos durante la fase preanalítica}

\section{Relacionadas con la solicitud del examen}

Es importante que los médicos emitan la solicitud de exámenes con letra legible y, si es posible, incluyan el diagnóstico presuntivo o los datos de interés que puedan ser útiles para el bacteriólogo o microbiólogo que los va a realizar y para la interpretación de los resultados [2]. Por su parte, es recomendable que las secretarias o el personal encargado del ingreso de la información del paciente al Sistema de Información del Laboratorio (SIL) verifiquen la identidad y los exámenes ingresados al sistema con la orden médica.

Así mismo, se recomienda informar verbalmente y por escrito a los pacientes acerca de las condiciones preanalíticas que deben cumplir, tanto las condiciones generales como el ayuno de 12 horas previas a la toma de la muestra, abstenerse de actividad física intensa, ingesta de alcohol y medicamentos 24 horas antes de la flebotomía, como las especiales que puedan requerir los exámenes $[18,25]$.

\section{Relacionadas con la toma de muestra}

Dentro de los procesos básicos que se deben incluir en la toma de muestra para evitar errores se encuentran:

- Comparar el nombre, el número de identificación y demás identificadores positivos del paciente con la hoja de solicitud de exámenes y las etiquetas que se emplearán para marcar los tubos y demás recipientes. Se recomienda el empleo de mínimo dos identificadores positivos del paciente [26].

- Siempre firmar la hoja de solicitud de exámenes [20].

- Si existen dudas acerca de las condiciones para la toma de muestra se recomienda que el bacteriólogo, microbiólogo o personal encargado del procedimiento se remita al manual de toma de muestra [20], el cual debe estar disponible en dicha área y debe estar actualizado y revisado por los líderes de los procesos.

- Marcar los tubos y recipientes antes de realizar la toma de la muestra y no permitir que alguien más lo haga [20].

- Para la toma de muestra por venopunción se deben tener en cuenta las siguientes consideraciones:

- Preparar el material necesario para el procedimiento (véase figura 2). 


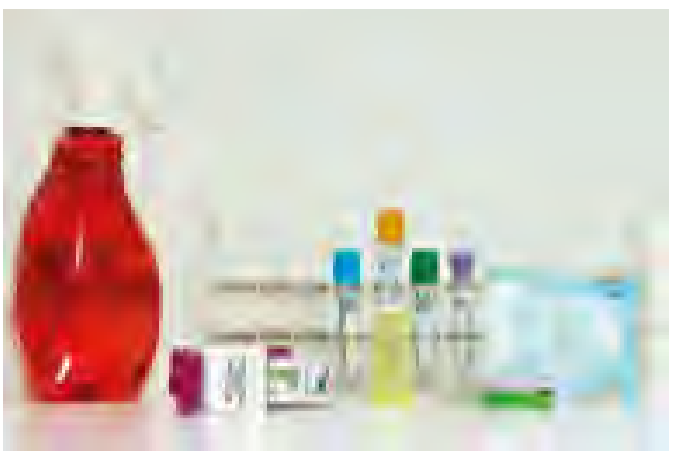

Figura 2. Material para la venopunción: alcohol, torniquete, camisa para aguja, aguja, algodón, tubos al vacío para recolección de sangre. Cortesía del Laboratorio Clínico Hematológico S.A. Medellín, Colombia.

- Realizar previa asepsia con algodón o gasa impregnada de alcohol, aplicando movimientos circulares desde el centro hacia afuera [27].

- Colocar el torniquete entre $7,5 \mathrm{~cm}$ y $10 \mathrm{~cm}$ por encima del punto de venopunción y no dejarlo más de un minuto $[27,28]$, pues cuando se deja aplicado por más tiempo se produce hemoconcentración y se altera el equilibrio sanguíneo entre el componente líquido y el componente celular [17].

- El orden recomendado para la toma de la muestra en los casos en que se requieran diferentes tubos para las diversas pruebas solicitadas al paciente es: botella de hemocultivo, tubo citratado (tapa azul cielo), sin aditivo (tapa roja), con activadores de la coagulación (tapa amarilla o gris-roja), con heparina de sodio (tapa verde oscuro), con heparina de litio (tapa verde claro), con ácido etilendiaminotetraacético (EDTA; tapa lila), con dextrosa citrato (tapa amarillo pálido) y con oxalato/fluoruro (tapa gris clara) [28] (véase figura 3).

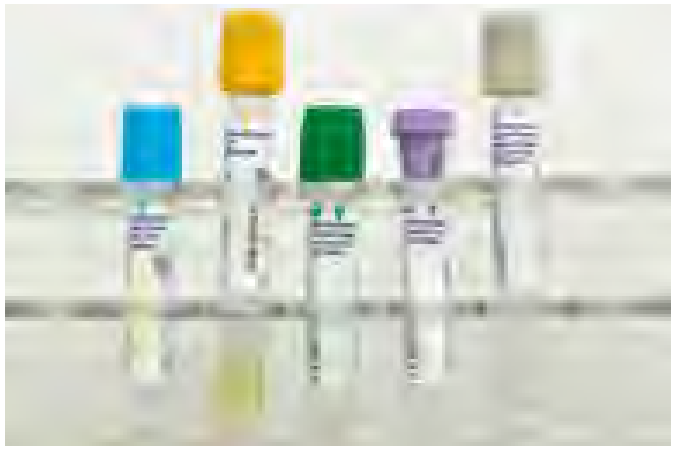

Figura 3. Tubos más utilizados para la toma de muestras por venopunción. Obsérvense, de izquierda a derecha, en su orden de llenado: tubo citratado (tapa azul cielo), tubo con gel separador con activadores de la coagulación (tapa amarilla), tubo con heparina de sodio (tapa verde oscuro), tubo con EDTA (tapa lila) y tubo con oxalato (tapa gris clara). Cortesía del Laboratorio Clínico Hematológico S.A. Medellín, Colombia.

- Seleccionar el tipo de aguja más adecuado según los exámenes solicitados (véase figura 4) y los tipos de tubos que se deben tomar.

- El paciente debe evitar el estrés antes y durante la toma de muestra, debe permanecer quieto e informar a los bacteriólogos si está consumiendo algún medicamento para determinar su posible influencia en los resultados de los exámenes solicitados. 
Figura 4. Sistemas de agujas empleadas para las tomas de muestra. Obsérvense las agujas verdes (calibre 21G), tanto en su presentación normal como en las conocidas como "mariposa", y las agujas azules (calibre 23G), que son más delgadas. Cortesía del Laboratorio Clínico Hematológico S.A. Medellín, Colombia.

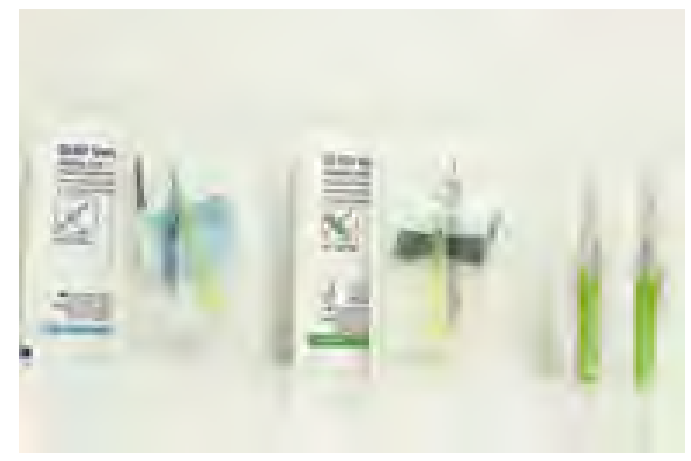

- Se recomienda que el personal del laboratorio y demás profesionales del área de la salud que estén involucrados en la toma de muestras participen en procesos de educación continua, ya que la falta de conciencia y la adopción de procedimientos inadecuados durante la fase preanalítica puede generar múltiples eventos adversos para la organización, el paciente y su respectivo manejo clínico [7].

\section{Relacionadas con el transporte,} la conservación, la preparación y distribución de la muestra

- Se debe tener presente cuáles muestras se pueden transportar de la sede de toma de muestra a la de procesamiento y cuáles se deben tomar solo en la sede en la que se procesan los exámenes.

- Según el tipo de muestra y la estabilidad del analito se deben establecer los tiempos máximos y las temperaturas óptimas de almacenamiento y transporte.

- Para las pruebas y muestras que aplique se debe conservar la cadena de frío durante el transporte y centrifugación de las muestras.

- Para las muestras que requieren centrifugación, en caso de que la muestra se extraiga en sitios diferentes al laboratorio clínico y se disponga de centrífugas en estos, se recomienda centrifugar los tubos de venopunción allí mismo para los exámenes de hemostasia [17].

- Los tubos secos se deben transportar en posición vertical con el tapón hacia arriba para que se forme por completo el coágulo y se evite posible hemólisis por la agitación de las muestras [27]. Si los tubos ya están centrifugados se deben conservar en posición vertical para evitar posibles interferencias [17].

- Se debe estandarizar el tiempo y las revoluciones por minuto a las cuales se centrifugan las muestras, dependiendo de los análisis a realizar. 
- En caso de que se transfiera la muestra a un tubo secundario este se debe marcar con todos los identificadores positivos del paciente.

- Las hojas de trabajo disponibles en el SIL permiten una correcta distribución de las muestras a todas las secciones del laboratorio para asegurar que todas las muestras se procesan para todas las pruebas solicitadas [17].

\section{Recomendaciones para la toma de muestras según el área de interés para el diagnóstico hematológico}

\section{Hemostasia}

Las pruebas de hemostasia son quizá el grupo de ensayos más sensibles a las condiciones en las que se toma la muestra, destacándose el tipo de aguja empleado, la concentración del anticoagulante, la relación anticoagulante:muestra, la aplicación del torniquete, las punciones traumáticas y la temperatura de almacenamiento y de transporte, entre otros factores. En esta ocasión se darán las recomendaciones generales para las pruebas básicas y especializadas de coagulación, en donde se incluyen la determinación de los factores y las proteínas de la coagulación, la prueba de mezclas y el estudio de inhibidores. Las pruebas de función plaquetaria como el PFA-100, el PFA-P2Y y la agregación plaquetaria con diferentes agonistas serán analizadas posteriormente en esta revisión.

\section{Preparación del paciente}

Las condiciones del paciente corresponden, en general, a las que aplican a todas las pruebas de coagulación, es decir, evitar dietas ricas en grasa entre 8 y 12 horas previas a la toma de muestra, evitar ejercicio físico intenso 24 horas antes, evitar el estrés, evitar el cigarrillo mínimo dos horas antes de la toma de la muestra y permanecer en reposo mínimo 15 minutos antes de la venopunción. Desde que sea posible se recomienda la toma de la muestra entre las 7:00 am y las 9:00 am para evitar variaciones relacionadas con los ciclos circadianos [28-30].

En el caso de que el paciente esté tomando anticoagulantes, el médico, de acuerdo al propósito del examen (descubrir la etiología de la trombosis o hacer seguimiento del efecto terapéutico de un medicamento), debe definir si se suspende o no el medicamento. En la tabla 2 se resume el efecto del consumo de anticoagulantes, antiagregantes o la presencia de un episodio trombótico, previo a la toma de la muestra, sobre las pruebas de coagulación [31].

\section{Toma de la muestra}

Debido a que el citrato de sodio afecta la concentración del calcio disponible para promover la formación del coágulo, se debe estandarizar la concentración de ci- 


\begin{tabular}{|c|c|c|}
\hline Evento preanalítico & $\begin{array}{l}\text { Efecto sobre pruebas } \\
\text { rutinarias }\end{array}$ & Efecto sobre pruebas especializadas \\
\hline $\begin{array}{l}\text { Toma de la muestra } \\
\text { durante la terapia } \\
\text { con heparina [31] }\end{array}$ & $\begin{array}{l}\text { Principalmente prolonga- } \\
\text { ción del tiempo de trom- } \\
\text { boplastina parcial activado }\end{array}$ & $\begin{array}{l}\text { Falsa disminución de antitrombina } \\
\text { Falsa presencia de anticoagulante lúpico }\end{array}$ \\
\hline $\begin{array}{l}\text { Toma de la muestra } \\
\text { durante la terapia } \\
\text { con antagonistas de } \\
\text { la vitamina } \mathrm{K}[31,32]\end{array}$ & $\begin{array}{l}\text { Principalmente prolonga- } \\
\text { ción del tiempo de pro- } \\
\text { trombina }\end{array}$ & $\begin{array}{l}\text { Falsa disminución de la proteína C, la proteína S } \\
\text { o ambas } \\
\text { Falsa resistencia a la proteína C activada } \\
\text { Falsa presencia de anticoagulante lúpico } \\
\text { Falsa presencia de resistencia a la proteína C } \\
\text { Disminución de niveles del factor II, factor VII, } \\
\text { factor IX y factor X } \\
\text { Alteración en la identificación de inhibidores de la } \\
\text { coagulación }\end{array}$ \\
\hline $\begin{array}{l}\text { Toma de la muestra } \\
\text { durante la terapia } \\
\text { con inhibidores di- } \\
\text { rectos de la trombina } \\
{[33-35]}\end{array}$ & $\begin{array}{l}\text { Posible prolongación del } \\
\text { tiempo de tromboplastina } \\
\text { parcial activado } \\
\text { Prolongación del tiempo de } \\
\text { protrombina según la sen- } \\
\text { sibilidad del reactivo }\end{array}$ & $\begin{array}{l}\text { Falsa presencia de resistencia a la proteína C } \\
\text { Alteración del tiempo de trombina según el anticoa- } \\
\text { gulante que consume el paciente } \\
\text { Alteración de la actividad del factor Xa }\end{array}$ \\
\hline $\begin{array}{l}\text { Toma de la muestra } \\
\text { justo después de un } \\
\text { evento trombótico } \\
\text { [31] }\end{array}$ & $\begin{array}{l}\text { Acortamiento del tiempo } \\
\text { de tromboplastina parcial } \\
\text { activado }\end{array}$ & $\begin{array}{l}\text { Falsa disminución de antitrombina } \\
\text { Falsa disminución de la proteína C y la proteína } \mathrm{S} \\
\text { Riesgo de falsa ausencia de anticoagulante lúpico }\end{array}$ \\
\hline
\end{tabular}

trato que se va a emplear en el laboratorio y, con base en esta, establecer los intervalos biológicos de referencia. La concentración recomendada de citrato trisódico es de 3,2\% con tampón, y la relación recomendada es de una parte de anticoagulante por nueve partes de sangre. Cuando el hematocrito del paciente es inferior al $30 \%$ o superior al $55 \%$ se sugiere calcular la concentración de anticoagulante específica para no alterar los niveles de calcio $[29,36]$. Además, se requiere una correcta mezcla por inversión del tubo inmediatamente después del llenado del tubo para que no se coagule parcialmente la muestra [25].

También se recomienda el empleo de agujas que tengan un calibre intermedio, idealmente de $21 \mathrm{G}$ (agujas verdes), ya que las agujas con diámetros mayores favorecen las punciones traumáticas y la consecuente liberación de fragmentos vasculares que alteren la hemostasia. Por su parte, las agujas de diámetros iguales o menores que 23G (agujas azules), al ser más delgadas, prolongan el tiempo de recolección de la muestra y el gradiente de presión que se genera puede provocar hemólisis o inducir la activación de leucocitos y plaquetas. Aunque no es lo ideal, suponiendo que las muestras se tomen con jeringa, se recomienda que se usen de polipropileno con capacidad de $3 \mathrm{~mL}$ a $5 \mathrm{~mL}$, ya que las jeringas más grandes producen una presión negativa excesiva que genera gran riesgo de hemólisis y de activación celular [28]. 
Respecto al uso de las agujas conocidas como «mariposas», su uso para pruebas de hemostasia está avalado siempre que se usen de $21 \mathrm{G}$ (agujas verdes) y que el primer tubo que se tome sea descartado, ya que por el efecto del vacío se recolecta menos sangre (aproximadamente $500 \mu \mathrm{L}$ ), y que se tome un segundo tubo con llenado apto para su procesamiento y sin alteración de la relación anticoagulante:muestra $[28,36,37]$.

Otras recomendaciones esenciales para la toma de la muestra en hemostasia es evitar al máximo tomarla de catéter, ya que se pueden alterar el tiempo de tromboplastina parcial activado (APTT) y el tiempo de trombina (TT) [36]. Respecto al uso del torniquete se ha observado que cuando se aplica durante más de un minuto, con mayor efecto cuando supera los tres minutos, se incrementan los niveles del factor VIII, el factor von Willebrand y el fibrinógeno, mientras que se acortan los tiempos de protrombina (PT) y tromboplastina parcial activado, e incluso se puede activar la fibrinólisis $[28,29,36]$.

En un estudio se reportó que uno de los principales problemas que se presentan durante la fase preanalítica es el llenado incompleto de los tubos para las pruebas de coagulación (véase figura 5), lo que altera la relación anticoagulante:muestra [4]. Por tal razón, en todos los casos se debe garantizar el llenado completo del tubo, es decir, hasta agotar el vacío. La conservación de esta relación resulta crítica, ya que el exceso de anticoagulante prolonga los tiempos de coagulación $[25,29]$, especialmente el tiempo de tromboplastina parcial activado [36]; de hecho, si se llena solo el $89 \%$ del tubo se observa un aumento estadísticamente significativo del tiempo de tromboplastina parcial activado, y cuando solo se llena el $78 \%$ de la capacidad del tubo se afectan significativamente los valores del factor VIII y el fibrinógeno [28].

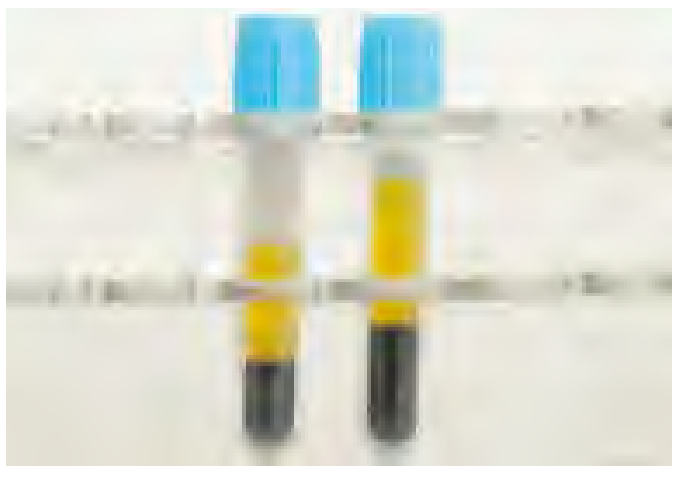

Figura 5. Tubos citratados para pruebas de coagulación. Obsérvese a la izquierda un tubo mal llenado y a la derecha bien llenado. Cortesía del Laboratorio Clínico Hematológico S.A. Medellín, Colombia.

\section{Centrifugación, transporte y almacenamiento de las muestras}

Después de la toma de las muestras estas se deben conservar a temperatura ambiente (entre $15{ }^{\circ} \mathrm{C}$ y $25^{\circ} \mathrm{C}$ ) y centrifugar a $1.500 \mathrm{~g}$ por 15 minutos (para obtener el plasma pobre en plaquetas, PPP), a temperatura ambiente, antes de que 
transcurra una hora desde que fue tomada, ya que si pasa más tiempo sin centrifugarse se afecta el tiempo de tromboplastina parcial activado y los ensayos contra el factor Xa. Para las demás pruebas de coagulación las muestras pueden permanecer sin centrifugar hasta por cuatro horas $[28,29,38]$.

Además, las muestras siempre deben estar tapadas, ya que al permanecer destapadas por más de 30 minutos el dióxido de carbono se difunde y cambia el pH de la muestra, lo cual afecta el tiempo de protrombina, el tiempo de tromboplastina parcial activado y la actividad de los factores de coagulación $[29,38]$. Esto cobra especial interés cuando se están buscando inhibidores; de hecho, se ha observado que un cambio en el $\mathrm{pH}$ tan pequeño como 0,8 unidades induce la prolongación del tiempo de tromboplastina parcial activado [38,39].

En caso de que se requiera el transporte desde una sede periférica se recomienda enviar el plasma separado en un tubo secundario y adecuadamente marcado si no se puede garantizar el transporte y la separación de la muestra en menos de cuatro horas contadas a partir de la venopunción. Si se transporta la sangre total se recomienda centrifugar la muestra en la sede de la toma de la muestra, conservar el tubo en posición vertical durante el desplazamiento y a temperatura ambiente (entre $15^{\circ} \mathrm{C}$ y $25^{\circ} \mathrm{C}$ ) y recentrifugar antes del procesamiento $[29,38]$. Para el dímero $\mathrm{D}$ la temperatura de almacenamiento y transporte no debe superar los $20{ }^{\circ} \mathrm{C}$ [40].

El plasma, luego de ser centrifugado y separado en un tubo secundario, es estable para la mayoría de los estudios durante cuatro horas cuando se conserva a temperatura ambiente. Si el almacenamiento a temperatura ambiente supera este tiempo se observa una pérdida de la actividad del factor VIII, la proteína S y el dímero $D$, entre otros $[38,40]$, aunque algunos autores señalan estabilidad de ocho horas o más para la mayoría de pruebas de coagulación [41].

Las muestras para las pruebas de coagulación, en especial cuando el plasma no se ha separado ni transferido a un tubo secundario, no se deben refrigerar, ya que a temperaturas de refrigeración se activan las plaquetas y el factor VII, lo que puede inducir la pérdida de factor VIII y el factor von Willebrand $[29,38,42]$.

Para el almacenamiento de las muestras por periodos mayores a cuatro horas el plasma separado se debe congelar en ultracongeladores que garanticen como mínimo una temperatura de $-20{ }^{\circ} \mathrm{C}$, en los cuales es estable por un mes. Idealmente, el plasma se debe conservar a $-80^{\circ} \mathrm{C}$, en cuyo caso la estabilidad aumenta a seis meses para la mayoría de estudios. La muestra antes de ser procesada se debe descongelar mediante choque térmico, es decir, en baño maría a $37^{\circ} \mathrm{C}$ por cinco minutos, y procesar en menos de dos horas [38].

Respecto a la presencia de interferentes, en el evento de que se produzca hemólisis durante la toma o el transporte de la muestra se debe evitar el procesamiento 
de este espécimen, ya que la liberación de fosfolípidos, enzimas intracelulares, $A D P$, entre otros componentes celulares, pueden afectar positiva o negativamente el proceso de la hemostasia in vitro por la posible activación de los factores de coagulación [28]. Además, la hemoglobina puede afectar las determinaciones foto-ópticas de los autoanalizadores de coagulación, aunque algunos de ellos, tales como el Sysmex CS-2100i, disminuyen esta interferencia gracias a un chequeo inicial de la muestra a una longitud de onda de $575 \mathrm{~nm}$ en búsqueda de hemólisis; si esta es observada el ensayo se mide a una longitud de onda alternativa para evitar dicha interferencia. De forma similar, algunos autoanalizadores están equipados con el chequeo adicional de ictericia y lipemia para disminuir su interferencia en los resultados [43]. En la figura 6 se presenta un plasma hemolisado y lipémico en comparación de un plasma de aspecto normal.

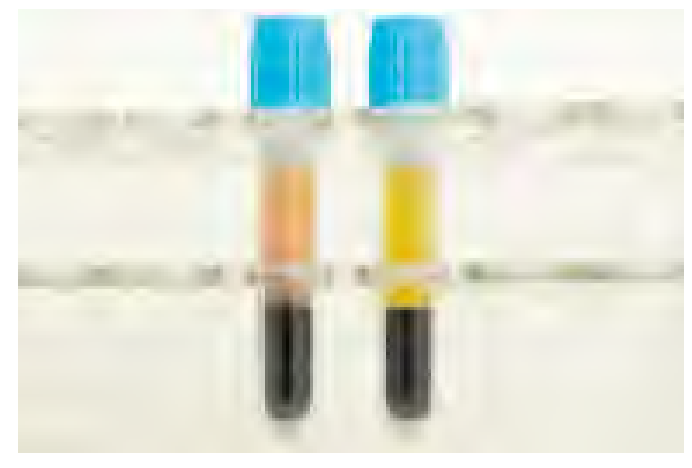

Figura 6. Tubos citratados con muestras de plasma hemolisado y lipémico (izquierda) y de aspecto normal (derecha). No se recomienda que se realicen las pruebas de coagulación cuando se tiene una muestra con al menos una de las características del primer tubo. Cortesía del Laboratorio Clínico Hematológico S.A. Medellín, Colombia.

\section{Pruebas de función plaquetaria}

Las pruebas de función plaquetaria como el PFA y la agregación tienen consideraciones preanalíticas específicas, en especial aquellas relacionadas con la preparación del paciente, el transporte, la centrifugación y la conservación de las muestras. No obstante, los aspectos relacionados con la toma de la muestra son prácticamente iguales a los mencionados anteriormente y no se realizará énfasis en ellos.

\section{Prueba de función plaquetaria PFA}

- Idealmente, la muestra se debe tomar en las horas de la mañana, debido a las variaciones circadianas $[28,44,45]$.

- Si el PFA-100 con cartuchos COL/EPI y COL/ADP se realiza como prueba tamiz o como prequirúrgico se debe suspender el consumo de aspirina mínimo siete días antes.

- En caso de que el PFA-100 con cartuchos COL/EPI y COL/ADP se realice para el seguimiento de la terapia antiagregante el paciente debe tomar la aspirina entre 30 minutos y una hora antes de la toma de la muestra [46]. 


\begin{tabular}{|c|c|c|}
\hline Medicamentos & Efecto sobre las plaquetas & Duración \\
\hline Ibuprofeno & Reversible & 24 horas \\
\hline Naproxeno & Reversible & Más de 4 días \\
\hline Tionopiridinas & Irreversible & 7 días \\
\hline Dipiridamol & Reversible & $\begin{array}{l}\text { Mínimo (usualmente no acarrea problemas } \\
\text { con los procedimientos) }\end{array}$ \\
\hline $\begin{array}{l}\text { Dipiridamol/aspirina de larga } \\
\text { acción }\end{array}$ & Reversible/irreversible & 5 días \\
\hline Cilostazol & Reversible & $\begin{array}{l}\text { Mínimo (usualmente no acarrea problemas } \\
\text { con los procedimientos) }\end{array}$ \\
\hline \multicolumn{3}{|c|}{$\begin{array}{l}\text { Tomado de "PFA-100: una nueva prueba de función plaquetaria sustituta del tiempo de sangría" por G. Campuzano- } \\
\text { Maya, 2013, Medicina \& Laboratorio, 19, p. } 536 \text { [50]. }\end{array}$} \\
\hline
\end{tabular}

- Cuando se realice el PFA con cartucho PFA-P2Y2 para el seguimiento de inhibidores del P2Y12, como el clopidogrel, el paciente debe tomar el medicamento siguiendo las recomendaciones médicas y tener completa adherencia al tratamiento por lo menos una semana antes de la toma de la muestra; además, se debe tomar el medicamento entre una a 24 horas antes de la toma de la muestra $[47,48]$.

- Independiente del propósito del estudio, los pacientes deben evitar, como mínimo 10 días, el consumo de otros medicamentos que afectan la función plaquetaria (véase tabla 3), así como medicamentos naturistas que interfieran con el estudio.

- En cuanto a la toma de la muestra, además de las condiciones aplicables a todas las pruebas de coagulación, si se analiza el primer tubo obtenido en la venopunción en vez del segundo se observan tiempos de cierre acortados [49].

- Uno de los aspectos preanalíticos más importantes para la realización del PFA es que las muestras no se deben centrifugar, pues esto activa las plaquetas. En caso que se centrifugue por error se debe realizar una nueva venopunción $[28,45,50]$.

- La muestra debe permanecer en reposo y a temperatura ambiente $\left(15^{\circ} \mathrm{C}\right.$ a $25^{\circ} \mathrm{C}$ ) durante mínimo 10 minutos y máximo tres horas $[45,50]$.

- No se deben procesar las muestras hemolisadas [28].

- La presencia de microcoágulos pueden afectar la prueba por obstrucción del flujo, por lo que se requiere la toma de una nueva muestra $[45,50]$. 
- Los niveles anormalmente bajos del hematocrito (menor al 35\%) y del recuento plaquetario (menor que $150.000 / \mu \mathrm{L}$ ) pueden producir alargamiento en el «tiempo de cierre» $[45,50]$.

- Suponiendo que la muestra deba ser transportada se debe conservar a temperatura ambiente y dejar en reposo por 30 minutos antes de realizar el análisis. Aunque no se han observado alteraciones significativas, se recomienda evitar el uso de tubo neumático $[28,45,50]$.

\section{Agregometría plaquetaria}

Para las pruebas de agregación plaquetaria es de suma importancia garantizar una buena toma de la muestra, donde se eviten punciones traumáticas y hemólisis de las muestras. Además, se requiere estricto ayuno, pues la lipemia afecta la turbidez de la muestra y las mediciones realizadas.

Se debe evitar el ejercicio moderado por lo menos una hora antes de la toma de la muestra para evitar un falso aumento en la respuesta a los agonistas ADP y epinefrina [30]. Debido al ciclo circadiano la venopunción se debe realizar antes de las 10:00 am. En cuanto al consumo de medicamentos, a excepción de la agregometría plaquetaria con ácido araquidónico, se debe suspender el consumo de antinflamatorios no esteroideos, aspirina, antibióticos, medicamentos naturistas, entre otros interferentes de la función plaquetaria, por lo menos 10 días antes de la toma de la muestra [51-53].

El transporte, conservación y centrifugación de las muestras se debe realizar en todo momento a temperatura ambiente para evitar la activación espontánea de las plaquetas, mantener en posición vertical y evitar movimientos bruscos antes de su procesamiento. Idealmente, las muestras se deben tomar en las sedes de procesamiento y no se recomienda el transporte en tubo neumático [28].

El plasma rico en plaquetas (PRP) se obtiene mediante la centrifugación a 170$200 \mathrm{~g}$ durante 10 minutos, mientras que el plasma pobre en plaquetas se obtiene al centrifugar a $1.500 \mathrm{~g}$ durante 15 minutos. Luego de la centrifugación, las muestras se deben procesar entre 30 minutos y cuatro horas $[28,51,53]$. En la tabla 4 se resumen las principales condiciones preanalíticas dependiendo del estudio de agregometría plaquetaria que se vaya a realizar.

\section{Hematología general}

\section{Hemograma}

En hematología, específicamente para el hemograma y el extendido de sangre periférica, la toma de la muestra es la parte más crítica de la fase preanalítica. Upreti y colaboradores describen que alrededor del $1,3 \%$ de las muestras de hematología son 


\begin{tabular}{|c|c|c|c|c|}
\hline $\begin{array}{l}\text { Tipo de } \\
\text { agregación }\end{array}$ & Preparación del paciente & $\begin{array}{l}\text { Cantidad } \\
\text { de tubos }\end{array}$ & $\begin{array}{l}\text { Protocolo de } \\
\text { centrifugación }\end{array}$ & Conservación de las muestras \\
\hline $\begin{array}{l}\text { Agregación } \\
\text { plaquetaria, } \\
\text { perfil hemo- } \\
\text { rrágico }\end{array}$ & $\begin{array}{l}\text { Suspender antinflamato- } \\
\text { rios, antiagregantes, an- } \\
\text { tibióticos, medicamentos } \\
\text { naturistas }\end{array}$ & 4 & $\begin{array}{l}1 \text { tubo para plas- } \\
\text { ma pobre en pla- } \\
\text { quetas } \\
3 \text { tubos para } \\
\text { plasma rico en } \\
\text { plaquetas }\end{array}$ & $\begin{array}{l}\text { Conservar a temperatura am- } \\
\text { biente } \\
\text { Analizar entre } 30 \text { minutos y } 4 \\
\text { horas después de la toma de } \\
\text { la muestra }\end{array}$ \\
\hline $\begin{array}{l}\text { Agregación } \\
\text { plaquetaria } \\
\text { inducida por } \\
\text { ristocetina } \\
\text { (RIPA) }\end{array}$ & $\begin{array}{l}\text { Suspender antinflamato- } \\
\text { rios, antiagregantes, an- } \\
\text { tibióticos, medicamentos } \\
\text { naturistas }\end{array}$ & 3 & $\begin{array}{l}1 \text { tubo para plas- } \\
\text { ma pobre en pla- } \\
\text { quetas } \\
2 \text { tubos para } \\
\text { plasma rico en } \\
\text { plaquetas }\end{array}$ & $\begin{array}{l}\text { Conservar a temperatura am- } \\
\text { biente } \\
\text { Analizar entre } 30 \text { minutos y } 4 \\
\text { horas después de la toma de } \\
\text { la muestra }\end{array}$ \\
\hline $\begin{array}{l}\text { Agregación } \\
\text { plaquetaria, } \\
\text { cofactor de } \\
\text { ristocetina }\end{array}$ & $\begin{array}{l}\text { Suspender antinflamato- } \\
\text { rios, antiagregantes, an- } \\
\text { tibióticos, medicamentos } \\
\text { naturistas }\end{array}$ & 1 & $\begin{array}{l}1 \text { tubo para plas- } \\
\text { ma pobre en pla- } \\
\text { quetas }\end{array}$ & $\begin{array}{l}\text { Conservar a temperatura am- } \\
\text { biente si se va a procesar antes } \\
\text { de } 4 \text { horas } \\
\text { Si se va a procesar otro día, la } \\
\text { muestra se puede almacenar } \\
\text { congelada a }-20^{\circ} \mathrm{C} \text { durante } \\
1 \text { mes } \\
\text { Para el procesamiento des- } \\
\text { congelar a } 37^{\circ} \mathrm{C} \text { durante } 5-10 \\
\text { minutos y procesar en menos } \\
\text { de } 2 \text { horas }\end{array}$ \\
\hline $\begin{array}{l}\text { Agregación } \\
\text { plaquetaria, } \\
\text { perfil trom- } \\
\text { bótico }\end{array}$ & $\begin{array}{l}\text { Suspender antinflamato- } \\
\text { rios, antiagregantes, an- } \\
\text { tibióticos, medicamentos } \\
\text { naturistas } \\
\text { Suspender aspirina si la } \\
\text { prueba se está realizan- } \\
\text { do para diagnóstico de } \\
\text { síndrome de plaquetas } \\
\text { pegajosas } \\
\text { Tomar antiagregante en } \\
\text { caso de que la prueba } \\
\text { sea para control del tra- } \\
\text { tamiento }\end{array}$ & 4 & $\begin{array}{l}1 \text { tubo para plas- } \\
\text { ma pobre en pla- } \\
\text { quetas } \\
3 \text { tubos para } \\
\text { plasma rico en } \\
\text { plaquetas }\end{array}$ & $\begin{array}{l}\text { Conservar a temperatura am- } \\
\text { biente } \\
\text { Analizar entre } 30 \text { minutos y } 4 \\
\text { horas después de la toma de } \\
\text { la muestra }\end{array}$ \\
\hline $\begin{array}{l}\text { Agregación } \\
\text { plaquetaria, } \\
\text { ácido araqui- } \\
\text { dónico }\end{array}$ & $\begin{array}{l}\text { Tomar aspirina el día de } \\
\text { la prueba, } 30 \text { minutos a } \\
1 \text { hora antes de la toma } \\
\text { de la muestra }\end{array}$ & 2 & $\begin{array}{l}1 \text { tubo para plas- } \\
\text { ma pobre en pla- } \\
\text { quetas } \\
1 \text { tubo para plas- } \\
\text { ma rico en pla- } \\
\text { quetas }\end{array}$ & $\begin{array}{l}\text { Conservar a temperatura am- } \\
\text { biente } \\
\text { Analizar entre } 30 \text { minutos y } 4 \\
\text { horas después de la toma de } \\
\text { la muestra }\end{array}$ \\
\hline
\end{tabular}

rechazadas por errores durante la fase preanalítica, específicamente en actividades relacionadas con la toma de la muestra, tales como la mala identificación de los pacientes, toma de la muestra en un tubo inadecuado, muestra coagulada, hemolisada o hemodiluída $[56,57]$.

Es esencial que el paciente conserve la calma antes y durante la venopunción, ya que el estrés, la ansiedad y la hiperventilación pueden elevar el recuento de leucocitos [25]; además, la ansiedad y el trauma físico o psicológico induce la inversión de la proporción neutrófilos-linfocitos $[58,59]$. También se debe evitar tomar la muestra 
después de una inyección de epinefrina, pues aumenta el recuento total de leucocitos y afecta el recuento diferencial [58]. Por su parte, si el paciente realizó ejercicio antes de asistir al laboratorio debe permanecer por lo menos 30 minutos en reposo, ya que durante el ejercicio extenuante se incrementa el recuento de leucocitos hasta $30 \times 10^{3} / \mu \mathrm{L}$ no solo debido al desprendimiento del compartimiento circulante que permanece adherido al endotelio vascular, sino por el efecto del cortisol $[58,60]$.

El paciente debe evitar el cigarrillo antes de la toma de la muestra, ya que este aumenta la hemoglobina, el hematocrito y el volumen medio corpuscular (VCM) debido a la presencia de carboxihemoglobina circulante, aumento que dependerá de la cantidad y la frecuencia del consumo de cigarrillo; además, aumenta el recuento de neutrófilos (con posibles alteraciones en su funcionamiento) y el recuento de linfocitos (principalmente CD4 ${ }^{+}$) [58].

Al igual que para las pruebas de hemostasia, el torniquete se debe aplicar durante el menor tiempo posible, pues se puede presentar hemoconcentración. Si el torniquete se aplica por más de 60 segundos los parámetros del hemograma que más se afectan son los recuentos de plaquetas, leucocitos, monocitos y neutrófilos. Asimismo, la muestra se debe mezclar inmediatamente para que no se formen microcoágulos que alteren el recuento de plaquetas y la determinación de los índices plaquetarios como el volumen plaquetario medio (VPM) [23].

De forma similar, se debe tener cuidado con producir hemólisis durante la toma de la muestra, como puede suceder cuando se usan agujas muy delgadas, las muestras se toman de una línea intravenosa, la venopunción se realiza en venas con mayor riesgo de generar hemólisis ( $p$. ej. la vena basílica) o se mezclan los tubos con mucha fuerza, entre otras situaciones $[56,61]$. En caso de que se produzca hemólisis se altera el recuento de glóbulos rojos y el hematocrito sin que se afecte la concentración de la hemoglobina y el volumen corpuscular medio.

El anticoagulante de elección para la recolección de muestras para hematología es el EDTA dipotásico ( $\mathrm{K}_{2}$ EDTA), el cual actúa como quelante de calcio y evita la agregación plaquetaria. A diferencia del EDTA tripotásico ( $\left.K_{3} E D T A\right)$, el $K_{2}$ EDTA altera en menor proporción la morfología celular en las dos primeras horas posteriores a la recolección de la muestra; además, no tiene efecto dilucional, pero sí un menor efecto sobre el volumen plaquetario medio. Lo anterior depende de la conservación de una correcta relación anticoagulante:muestra, lo cual se favorece con el empleo de tubos al vacío [62-64].

En el evento de que se produzca un llenado insuficiente de los tubos la concentración de EDTA aumenta, lo que eleva el riesgo de inducir alteraciones artefactuales en los recuentos y en las constantes corpusculares (véase figura 7). Por ejemplo, ante el contacto con el $\mathrm{K}_{2}$ EDTA, en especial cuando no se conserva la relación anticoagulante:muestra, se induce un aumento en el volumen medio corpuscular, al 
Figura 7. Tubos con EDTA utilizados para el hemograma el extendido de sangre periférica. Obsérvese a la izquierda un tubo mal llenado y a la derecha bien llenado. Cortesía del laboratorio Clínico Hematológico S.A. Medellín, Colombia.

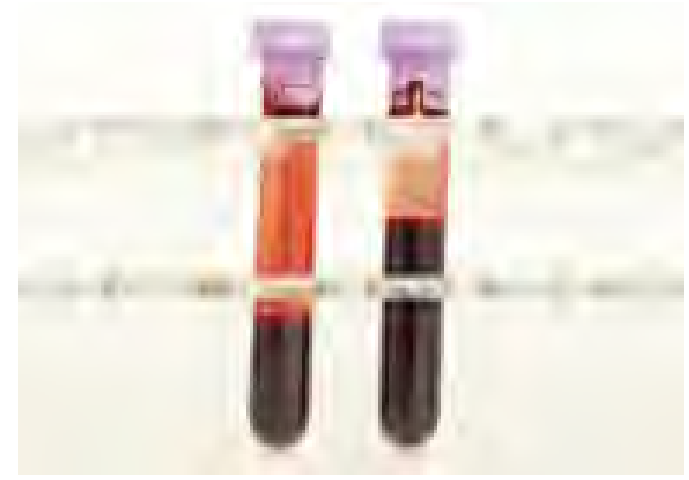

igual que un incremento en el volumen medio plaquetario a causa de una «hinchazón» de las plaquetas que, en el peor de los casos, se podrían reventar y producir fragmentos plaquetarios que pueden ser contados falsamente como plaquetas $y$ alterar su recuento [65].

En relación con la estabilidad de las muestras y el tiempo y la temperatura de almacenamiento a la que se pueden obtener resultados confiables, esto depende del autoanalizador de hematología empleado, ya que la estabilidad de la muestra para la determinación de los parámetros del hemograma obedece directamente a los principios de medida que incluya el autoanalizador. En general, las muestras se deben procesar antes de dos horas para evitar alteraciones relacionadas con el anticoagulante [64]. Para la serie XN de Sysmex la estabilidad máxima de las muestras es de 24 horas si se conservan a temperaturas entre $20^{\circ} \mathrm{C}$ y $25^{\circ} \mathrm{C}$, mientras que la estabilidad es de 48 horas si se almacenan entre $2^{\circ} \mathrm{C}$ y $8^{\circ} \mathrm{C}[66,67]$.

Por otra parte, cuando el paciente informa, o es un paciente conocido en el servicio, sobre la presencia de interferentes como pseudotrombocitopenia o hemaglutinación, el personal de toma de muestra debe tener el entrenamiento y conocimiento para la toma de los tubos adicionales o las condiciones especiales de transporte y almacenamiento que se requieran.

\section{Extendido de sangre periférica}

El extendido de sangre periférica se realiza en sangre anticoagulada con EDTA. Para su procesamiento, idealmente, no deben transcurrir más de dos horas desde la toma de la muestra, ya que este anticoagulante altera la morfología de los leucocitos, los eritrocitos y las plaquetas, y el efecto se acentúa con el tiempo de contacto $[64,68]$. Por ejemplo, la alteración de la cromatina de los neutrófilos causada por el EDTA se acentúa después de tres horas de la toma de la muestra y puede volver irreconocible a la célula e incluso inducir su desintegración, en especial, cuando no se llena por completo el tubo y aumenta la concentración de EDTA. Con referencia a las plaquetas, a medida que transcurre el tiempo pierden su forma discoide, adoptan una 
presencia esférica y aumentan falsamente de tamaño, lo que lleva a la observación de falsas macroplaquetas en el extendido de sangre periférica [65].

En cuanto a la técnica se requiere un entrenamiento previo del personal para obtener extendidos con campos y coloración óptima (véase figura 8) [69,70]. Idealmente, se debería disponer de sistemas automatizados para la realización y la coloración de los extendidos, como el Sysmex SP-10, en el cual, con una estandarización previa, se logra el control de la calidad del extendido y su coloración al considerar, incluso, el hematocrito para el ángulo de extensión que emplea el equipo. Independiente de que se realice de una forma manual o automatizada, la obtención de un extendido de buena calidad influenciará en el estudio morfológico y el recuento diferencial de leucocitos que se realice a partir de la observación microscópica [70].

Figura 8. Extendido de sangre periférica con distribución y coloración óptima (izquierda) y de mala calidad (derecha). Cortesía del Laboratorio Clínico Hematológico S.A. Medellín, Colombia.

En el caso de la realización de extendidos de sangre periférica manuales el laboratorio debe definir una forma homogénea, con adherencia de todo el personal, para marcar las placas y garantizar su trazabilidad, así como usar lápices de vidrio u otro utensilio que no se borre durante la tinción con Wright. De forma similar, en los autoanalizadores que realicen extendidos, se debe configurar previamente la impresión de identificadores positivos del paciente en cada placa [70].

En cuanto a la coloración de los extendidos, ya sea manual o automatizada, las cantidades y tiempos deben estar adecuadamente estandarizadas en cada laboratorio, así como la preparación de las soluciones de coloración y la necesidad de filtración periódica [70]. En general, la estandarización de la coloración debe disminuir o bien impedir la obtención de coloraciones ácidas, básicas, hidratadas, con precipitados, pálidas, entre otras.

\section{Hematopatología}

\section{Aspirado de médula ósea}

En la actualidad, el aspirado de médula ósea, obtenido principalmente de la cresta ilíaca, es de gran importancia para el diagnóstico de las enfermedades hematológicas e incluso de algunas enfermedades no hematológicas. El análisis medular, 
adicional a la evaluación morfológica (aspirado, impronta o biopsia) y al estudio inmunohisquímico tradicional, está acompañado del estudio por citometría de flujo, citogenética y biología molecular, según el caso [71]. En secciones posteriores se hará énfasis sobre las condiciones preanalíticas de cada una de estas técnicas.

De acuerdo a la sospecha diagnóstica se selecciona el procedimiento a realizar para la obtención de la médula ósea, bien sea biopsia, aspirado, o ambas, de lo cual van a depender las agujas a emplear (véase figura 9). Mediante aspiración es posible obtener partículas óseas que pueden ser extendidas en una lámina o laminilla para estudios morfológicos (aspirado); entretanto, con la biopsia se adquiere un pequeño fragmento de hueso para estudios morfológicos (impronta, corte histológico coloreado con hematoxilina-eosina) y para estudios de inmunohistoquímica (con marcadores específicos según la sospecha diagnóstica) [72]. Dado el alcance de este artículo, solo se hará énfasis en las condiciones de coloración de la impronta y el aspirado medular y no del preprocesamiento de las biopsias de médula ósea.

Figura 9. Material para aspirado o biopsia de médula ósea. Obsérvense agujas para biopsia (izquierda), agujas para aspirado (derecha), tubos con EDTA (tapa lila) y heparina de sodio (tapa verde) para la recolección de la muestra según el procedimiento a realizar, laminillas para la realización de extendidos, bisturí para el corte previo de la piel y micropipeta para capturar partículas de médula ósea. Cortesía del Laboratorio Clínico Hematológico S.A. Medellín, Colombia.

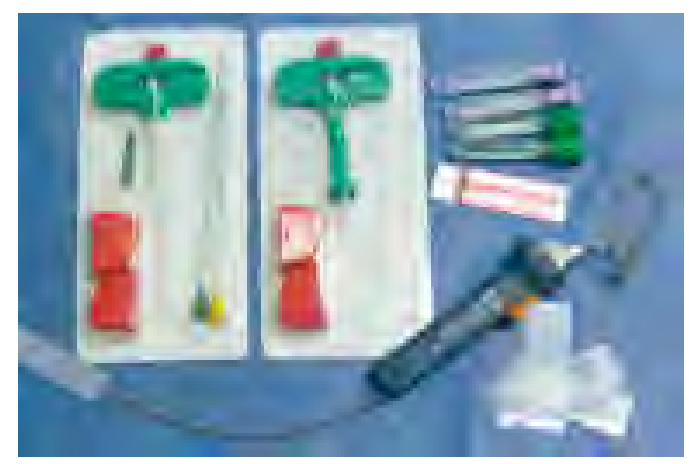

Antes de la toma de la muestra se le debe explicar al paciente o a su acudiente el procedimiento y los riesgos inherentes al mismo. Para la realización de este análisis se requiere obtener el consentimiento informado del paciente o de los padres si este es un menor de edad $[72,73]$. Tanto el aspirado como la biopsia de médula ósea son procedimientos especializados a cargo de los médicos hematólogos y médicos oncólogos [74], por lo que no se enfatizará en esta revisión en el procedimiento de la toma de la muestra.

Durante la toma de la muestra, bien sea el médico hematólogo, médico oncólogo o el bacteriólogo/microbiólogo que lo acompañe, se realizan los extendidos a partir de la primera fracción de sangre obtenida durante el aspirado medular $[72,75]$. Para esto existen varias técnicas, todas ellas con el propósito de «capturar» las partículas óseas y reducir la cantidad de sangre, eritrocitos y componente hemodiluido. La captura y la extensión de la muestra se debe hacer tan pronto como sea posible para evitar que la muestra se coagule y queden las partículas atrapadas $[72,76]$. De manera simultánea, el médico aprovecha y utiliza la misma 
punción medular para tomar las muestras de citometría, citogenética o biología molecular, según el caso $[76,77]$.

La impronta no es utilizada de rutina por todos los médicos hematólogos; no obstante, cobra gran importancia cuando el aspirado está seco o es de poca calidad y se pudo obtener un fragmento de biopsia de adecuada calidad. Para realizar la impronta se desplaza suavemente el fragmento de médula ósea entre dos láminas de vidrio [76].

Para el transporte del aspirado y la impronta es importante que las placas se sequen por completo antes de envolver o de poner en cualquier tipo de recipiente. Además, se debe tener cuidado en no quebrar las placas, dada la naturaleza de la muestra y el carácter invasivo del procedimiento. En cuanto a la coloración, tanto del aspirado como de la biopsia, se puede realizar con Wright o May-Grünwald Giemsa $[76,77]$.

\section{Citometría de flujo}

Para los estudios de citometría de flujo es importante que las órdenes médicas, o bien, las muestras, estén acompañadas por los datos del médico tratante ( $p$. ej. nombre completo, especialidad, información de contacto), así como los datos de la muestra (p. ej. tipo de muestra, fecha y hora de recolección), indicación del estudio (p. ej. historia médica, sospecha diagnóstica y tratamientos previos), información clínica relacionada con el momento de la toma de la muestra (p. ej. seguimiento durante la quimioterapia, recaída) y cualquier otra información relevante para el diagnóstico [78-80].

Entre las muestras que se pueden analizar por citometría de flujo para el diagnóstico hematológico se destacan la sangre periférica, la médula ósea, los ganglios linfáticos, las biopsias extranodales, el líquido pleural, el líquido cefalorraquídeo, entre otros tejidos $[81,82]$. Uno de los puntos críticos de la fase preanalítica de la citometría de flujo es el tiempo que transcurre desde la toma de la muestra hasta su procesamiento, ya que según el tipo de muestra, la clase de células que tenga y las condiciones de almacenamiento, se afectará la viabilidad y la integridad celular, así como la expresión antigénica [83]. Dadas las diferencias metodológicas entre los sistemas analíticos no se hará referencia a los protocolos de procesamiento de las muestras ( $p$. ej. lisis, lavado y tinción con fluorocromos, entre otros), sino que se hará énfasis en la recolección de la muestra y las condiciones de conservación y transporte.

En el momento de la toma de la muestra, en especial para el aspirado medular, se debe tener presente el contenedor que se va a emplear; por ejemplo, para las muestras de sangre periférica y de médula ósea se recomienda utilizar tubos anticoagulados con $\mathrm{K}_{2}$ EDTA $[78,83]$. Para los líquidos corporales se recomienda el uso de tubos estériles sin anticoagulante $y$, específicamente, para el líquido cefalorra- 
quídeo se recomiendan los tubos estériles con aditivos que mejoren la viabilidad celular como el Transfix ${ }^{\circledR}$ o el medio de cultivo RPMI suplementado con suero fetal bovino al 5\% [78]. En la tabla 5 se resumen los tipos de muestra más comúnmente empleadas para citometría, los contenedores que se deben usar para cada una y las condiciones de transporte y almacenamiento.

\begin{tabular}{|c|c|c|c|c|}
\hline $\begin{array}{l}\text { Tipo de } \\
\text { muestra }\end{array}$ & $\begin{array}{l}\text { Contenedores } \\
\text { empleados }\end{array}$ & $\begin{array}{l}\text { Sugerencias para la } \\
\text { toma de la muestra }\end{array}$ & $\begin{array}{l}\text { Temperatura de } \\
\text { transporte y alma- } \\
\text { cenamiento }\end{array}$ & $\begin{array}{l}\text { Tiempo máximo de al- } \\
\text { macenamiento previo al } \\
\text { procesamiento }\end{array}$ \\
\hline $\begin{array}{l}\text { Sangre } \\
\text { periférica } \\
{[78,83-86]}\end{array}$ & $\begin{array}{l}\text { Tubo con an- } \\
\text { ticoagulante } \\
\mathrm{K}_{2} \text { EDTA }\end{array}$ & Recolectar $5 \mathrm{~mL}$ & $\begin{array}{l}\text { Envío inmediato al } \\
\text { laboratorio } \\
\text { Conservar a tempe- } \\
\text { ratura ambiente }(18 \\
\left.{ }^{\circ} \mathrm{C}-25^{\circ} \mathrm{C}\right)\end{array}$ & $\begin{array}{l}\text { Se recomienda analizar } \\
\text { en las primeras } 2 \text { a } 6 \\
\text { horas } \\
\text { No debe exceder las } 24 \\
\text { a } 48 \text { horas }\end{array}$ \\
\hline $\begin{array}{l}\text { Médula ósea } \\
{[78,83,85,87]}\end{array}$ & $\begin{array}{l}\text { Tubo con an- } \\
\text { ticoagulante } \\
\mathrm{K}_{2} \text { EDTA }\end{array}$ & $\begin{array}{l}\text { Recolectar } 2 \mathrm{~mL} \\
\text { Evitar la hemodi- } \\
\text { lución con sangre } \\
\text { periférica }\end{array}$ & $\begin{array}{l}\text { Envío inmediato al } \\
\text { laboratorio } \\
\text { Conservar a tempe- } \\
\text { ratura ambiente }(18 \\
\left.{ }^{\circ} \mathrm{C}-25^{\circ} \mathrm{C}\right)\end{array}$ & $\begin{array}{l}\text { Se recomienda analizar } \\
\text { en las primeras } 2 \text { a } 6 \\
\text { horas } \\
\text { Si se sospecha de } \\
\text { tumores altamente } \\
\text { proliferativos se debe } \\
\text { procesar lo más rápido } \\
\text { posible } \\
\text { No debe exceder las } 24 \\
\text { a } 48 \text { horas }\end{array}$ \\
\hline $\begin{array}{l}\text { Líquido cefa- } \\
\text { lorraquídeo } \\
\text { [78] }\end{array}$ & $\begin{array}{l}\text { Tubo estéril, sin } \\
\text { anticoagulan- } \\
\text { tes, con aditi- } \\
\text { vos que mejo- } \\
\text { ren viabilidad } \\
\text { celular: } \\
\text { Transfix }{ }^{\circledR} \\
\text { Medio RPMI con } \\
\text { suero fetal bovi- } \\
\text { no al } 5 \%\end{array}$ & $\begin{array}{l}\text { Idealmente } 5 \mathrm{~mL} \text {, } \\
\text { puede ser menor } \\
\text { en pacientes pediá- } \\
\text { tricos }\end{array}$ & $\begin{array}{l}\text { Envío inmediato al } \\
\text { laboratorio } \\
\text { Conservar refrigera- } \\
\text { do entre } 2^{\circ} \mathrm{C} \text { y } 8^{\circ} \mathrm{C}\end{array}$ & $\begin{array}{l}\text { Sin aditivos: menos de } \\
4 \text { horas } \\
\text { Con Transfix }{ }^{\circledR}: 48-72 \\
\text { horas } \\
\text { Con medio RPMI con } \\
\text { suero fetal bovino al } \\
5 \%: 18 \text { horas }\end{array}$ \\
\hline $\begin{array}{l}\text { Otros líquidos } \\
\text { corporales } \\
{[78]}\end{array}$ & $\begin{array}{l}\text { Tubo estéril, sin } \\
\text { anticoagulante }\end{array}$ & Idealmente $5 \mathrm{~mL}$ & $\begin{array}{l}\text { Envío inmediato al } \\
\text { laboratorio } \\
\text { Conservar refrigera- } \\
\text { do entre } 2^{\circ} \mathrm{C} \text { y } 8{ }^{\circ} \mathrm{C}\end{array}$ & $\begin{array}{l}\text { Se recomienda analizar } \\
\text { en las primeras } 2 \text { a } 6 \\
\text { horas } \\
\text { No debe exceder las } 24 \\
\text { a } 48 \text { horas }\end{array}$ \\
\hline $\begin{array}{l}\text { Aspirados con } \\
\text { aguja fina } \\
{[78,88]}\end{array}$ & $\begin{array}{l}\text { Recipientes con } \\
\text { medio de trans- } \\
\text { porte isotónico, } \\
\text { como RPMI }\end{array}$ & $\begin{array}{l}\text { Variable, según es- } \\
\text { pécimen }\end{array}$ & $\begin{array}{l}\text { Envío inmediato al } \\
\text { laboratorio } \\
\text { Conservar refrigera- } \\
\text { do entre } 2^{\circ} \mathrm{C} \text { y } 8^{\circ} \mathrm{C}\end{array}$ & $\begin{array}{l}\text { Se recomienda analizar } \\
\text { inmediatamente o } \\
\text { en las primeras } 2 \text { a } 6 \\
\text { horas }\end{array}$ \\
\hline $\begin{array}{l}\text { Fragmentos } \\
\text { de ganglio } \\
\text { linfático o de } \\
\text { otros tejidos } \\
{[78,87,89]}\end{array}$ & $\begin{array}{l}\text { Recipientes con } \\
\text { medio de trans- } \\
\text { porte isotónico, } \\
\text { como RPMI } \\
\text { Recipientes con } \\
\text { PBS como solu- } \\
\text { ción tampón }\end{array}$ & $\begin{array}{l}\text { Variable, según es- } \\
\text { pécimen } \\
\text { Se debe enviar sus- } \\
\text { pendido en el medio } \\
\text { de transporte }\end{array}$ & $\begin{array}{l}\text { Envío inmediato al } \\
\text { laboratorio } \\
\text { Conservar refrigera- } \\
\text { do entre } 2^{\circ} \mathrm{C} \text { y } 8^{\circ} \mathrm{C}\end{array}$ & $\begin{array}{l}\text { Se recomienda analizar } \\
\text { en las primeras } 2 \text { a } 6 \\
\text { horas } \\
\text { Si se sospecha de } \\
\text { tumores altamente } \\
\text { proliferativos se debe } \\
\text { procesar lo más rápido } \\
\text { posible } \\
\text { No debe exceder las } 24 \\
\text { a } 48 \text { horas }\end{array}$ \\
\hline
\end{tabular}


Uno de los principales inconvenientes de la pérdida de la viabilidad es que las células no viables se pueden unir de forma inespecífica a los anticuerpos y, así, interferir en el análisis inmunofenotípico. En caso de que la muestra se haya obtenido mediante un procedimiento invasivo y se haya puesto en riesgo la viabilidad celular se debe hacer todo lo posible por obtener información diagnóstica útil, que evite un diagnóstico errado. En el evento de que se trate de una muestra irremplazable y que tenga una viabilidad muy baja se debe reportar cualquier población anormal que se observe; no obstante, la ausencia de una población neoplásica en una muestra de poca viabilidad no descarta la posibilidad de una neoplasia subyacente y el diagnóstico se debe fundamentar en otras pruebas de laboratorio [83].

Para preservar la viabilidad de las muestras, en especial aquellas de líquidos, se pueden agregar preservantes celulares como el Transfix ${ }^{\circledR}$, el cual, adicional a su gran utilidad para los líquidos cefalorraquídeos, se puede emplear para mejorar la estabilidad de las muestras de médula ósea. Adicional a los líquidos corporales, las muestras de tejidos sólidos y los linfomas agresivos tienen poca viabilidad, por lo que se deben procesar en la mayor brevedad posible $[78,83]$.

Por otra parte, dado el carácter invasivo de algunos procedimientos, en el caso de que una muestra se encuentre coagulada, por ejemplo, la de médula ósea, se debe procesar todo el volumen posible y dejar constancia de la calidad de la muestra cuando se emita el informe de laboratorio $[78,83,90]$.

\section{Citogenética}

Para las pruebas citogenéticas, como para cualquier otra prueba de laboratorio, antes de ser realizadas se le debe explicar al paciente en qué consiste y cómo va a ser tomada la muestra; además de brindarle las pautas específicas del laboratorio para la preparación para el examen. Para la realización de este análisis, idealmente, se requiere obtener el consentimiento informado del paciente o de los padres si este es un menor de edad [73].

En relación con la muestra, esta puede ser obtenida de numerosas fuentes, aunque el aspirado de médula ósea, tomada directamente por un médico especialista, es la más utilizada para el estudio de las enfermedades hematológicas premalignas y malignas. Los leucocitos no estimulados, obtenidos de sangre periférica por venopunción, también pueden ser utilizados para el análisis, especialmente si no se puede obtener un aspirado de médula ósea adecuado, con resultados satisfactorios cuando el conteo de blastos circulante es superior al 10\%-20\% [73,91,92]; no obstante, si en la sangre periférica no hay un número significativo de blastos hay una alta probabilidad de obtener fallas durante el cultivo de la muestra [87]. De igual manera, se pueden utilizar para el estudio diversos fluidos corporales y otros tejidos sólidos si se considera que ha ocurrido infiltración de las células he- 
matológicas neoplásicas a estos [93]; específicamente, los ganglios linfáticos son de utilidad cuando la sospecha diagnóstica es un linfoma [87].

El aspirado de médula ósea debe ser realizado por un médico hematólogo de acuerdo con las directrices locales para los procedimientos estériles [94], los cuales no serán comentados en este manuscrito. La muestra se debe tomar solo con las agujas diseñadas para este propósito y luego de que se hayan preparado los frotis de médula, utilizando la misma u otra jeringa estéril de $5 \mathrm{~mL}$ o $10 \mathrm{~mL}$ para aspirar la sangre medular y depositarla en tubos que contengan heparina de sodio libre de conservantes $[74,93,94]$. Aunque no es lo ideal, el volumen mínimo de recolección de sangre medular es de 1,0 mL [87]. Una vez tomada, la muestra se puede almacenar y transportar a temperatura ambiente por unas cuantas horas; si se espera un retraso en el envío o el análisis se debe conservar a $4{ }^{\circ} \mathrm{C}$ durante una noche o por máximo tres días, en cuyo caso se puede adicionar un medio de cultivo para preservar al máximo la viabilidad de la muestra [87,92-94].

Los primeros mililitros de médula ósea, subsecuentes a la porción de sangre que se destina para el extendido medular, contienen la mayor proporción de células y son la mejor muestra para el laboratorio de citogenética; por tal motivo, se debe evitar la hemodilución. Además, dado que el éxito del cultivo depende del número de células que se dividen activamente, la muestra debe ser procesada y cultivada inmediatamente luego de recibida en el laboratorio de citogenética para evitar la muerte celular $[87,93]$.

En cuanto a las muestras de sangre periférica se deben recolectar igualmente con jeringas o tubos al vacío que contengan heparina sódica como anticoagulante y ser cultivadas dentro de las primeras 24 horas de su recolección para mejores resultados $[93,95]$. La muestra se debe mantener a temperatura ambiente o refrigerada por encima de $4{ }^{\circ} \mathrm{C}$ hasta que pueda ser procesada. En ocasiones se recomienda añadir medio de cultivo a las muestras de sangre con poco volumen, ya que tienen tendencia a secarse, especialmente si se recogen en grandes contenedores. Si la muestra se recibe coagulada, con hielo o de más de 24 horas de recolección no debe ser procesada y se debe solicitar una nueva muestra. En caso de que no sea posible, el laboratorio de citogenética debe intentar recuperar el espécimen original, pues puede contener suficientes células viables para el análisis citogenético, a pesar de que el número y la calidad de estas se puedan ver comprometidos [93].

Durante la toma de las muestras de sangre periférica o médula ósea se debe tener presente que el anticoagulante indicado es la heparina de sodio y bajo ninguna circunstancia se pueden usar tubos de heparina de litio, ya que el litio impide la división celular y, por lo tanto, impide directamente la realización del cariotipo convencional [96]. 
Otras muestras aptas para el estudio citogenético son los ganglios linfáticos y otros tejidos. En el caso de muestras ganglionares, por ejemplo, aquellas obtenidas mediante aspiración, la muestra se debe recolectar con jeringa y enviar en un recipiente estéril con solución salina o medio RPMI, a temperatura ambiente o refrigerada por encima de $4^{\circ} \mathrm{C}$, y se debe procesar antes de que transcurran seis horas después de tomada la muestra [97].

Independiente del tipo, luego de ser recolectada, la muestra debe ser enviada al laboratorio de citogenética, acompañada de la orden del procedimiento a realizar $y$, cuando sea posible, del consentimiento informado; además, se debe comunicar al laboratorio de citogenética la sospecha diagnóstica, ya que el pretratamiento de la muestra y las condiciones del cultivo celular pueden variar según el tipo de neoplasia hematológica a estudiar [87]. Una vez en el laboratorio de citogenética la muestra debe ser ingresada al SIL y preparada para su análisis. La persona responsable debe verificar que la muestra esté debidamente etiquetada y acorde a la orden del servicio; además, que se encuentre en los recipientes, anticoagulantes o medios para la recolección y transporte adecuados y que las condiciones de temperatura y tiempo máximo de almacenamiento, color y volumen de la muestra, entre otros, sean los ideales [91]. Finalmente, el espécimen debe ser preparado para el cultivo celular y el posterior análisis citogenético, bien sea por cariotipo convencional o mediante hibridación fluorescente in situ (FISH); procesos posteriores a la fase preanalítica, que no serán abordados en esta revisión.

Para el FISH, adicional a la sangre fresca anticoagulada o en medio estéril, también se pueden aceptar aspirados medulares (sin fijar o coloreados) y tejidos embebidos en parafina, pues dado que no requiere de metafases se puede obviar el cultivo celular; además, no requiere células vivas. No obstante, se debe tener cuidado en que las placas y los tejidos enviados para FISH sí contengan células neoplásicas [87].

\section{Estudios moleculares}

Para los estudios moleculares, además de la información requerida para la identificación de cualquier otra muestra hematológica (p. ej. nombre completo, fecha de nacimiento, número del expediente médico), la solicitud de prueba debe incluir también la fecha y la hora de la recolección de la muestra, el tipo de muestra y la fuente, el médico encargado y la información de contacto, la información de facturación y la información clínica y de laboratorio pertinente. Igualmente, si aplica, se debe incluir una copia del informe de patología para asegurar una identificación exacta de los especímenes y poder correlacionar los resultados de las pruebas moleculares con el diagnóstico histopatológico [98].

Para el análisis molecular de los trastornos hematolinfoides se puede utilizar ADN genómico extraído de las células nucleadas obtenidas a partir de muestras de 
sangre total, médula ósea, tejido o fluidos corporales. Las muestras de sangre total y médula ósea deben ser recolectadas en tubos con EDTA, aunque el ácidocitrato-dextrosa (ACD) es también aceptable. En relación con la heparina se debe evitar su uso como anticoagulante pues interfiere con la reacción en cadena de la polimerasa $[98,99]$. Como se describió en la sección de citometría, los líquidos corporales se deben tomar en tubos estériles sin anticoagulantes [78].

Antes de la extracción del ADN, los especímenes pueden ser almacenados a temperatura ambiente temporalmente o refrigerados entre $2^{\circ} \mathrm{C}$ y $8{ }^{\circ} \mathrm{C}$ durante 24 y 72 horas, respectivamente, sin que se presente degradación significativa del ADN. Si se espera un retraso en la realización de las pruebas se deben almacenar a $-20{ }^{\circ} \mathrm{C}$, luego de eliminar los eritrocitos [100], pues la hemoglobina actúa como un inhibidor de la PCR y es liberada fácilmente durante la descongelación de los aspirados de médula o de sangre total [98].

Para el análisis molecular también se puede usar ARN obtenido de los aspirados de médula ósea y sangre total, recolectados directamente en tubos que contengan un agente estabilizador del ARN, los cuales son provistos por diversas casas comerciales. En caso contrario, los especímenes deben ser recolectados en tubos con EDTA y, al igual que los fluidos corporales, se deben colocar sobre hielo húmedo y ser transportados inmediatamente al laboratorio donde se realizará el análisis. La extracción de ARN se debe realizar máximo cuatro horas después de la recolección de la muestra; si no se puede realizar en el tiempo indicado los eritrocitos se deben eliminar y la muestra debe ser congelada a temperaturas inferiores a $-20^{\circ} \mathrm{C}$. Si no se cumplen estas recomendaciones se pueden obtener resultados erróneos a causa de la degradación del ARN o a la regulación alterada de la expresión génica. Una vez obtenido el material genético se procede inmediatamente con el análisis, generalmente, mediante reacción en cadena de la polimerasa cuantitativa en tiempo real (qRT-PCR) [98].

En caso que la muestra para qRT-PCR se tome durante el seguimiento del paciente y su propósito sea la definición de la respuesta a la quimioterapia, es importante que se evite la transfusión del paciente antes de la toma de la muestra, pues ello causaría un efecto de hemodilución [99].

Por otra parte, dependiendo del propósito del estudio (diagnóstico o seguimiento) y el tipo de neoplasia hematológica de interés, se debe tener presente si la muestra ideal es la médula ósea o la sangre periférica. Por ejemplo, para la detección del transcripto fusión BCR-ABL mediante la qRT-PCR en pacientes con leucemia mieloide crónica, es ideal que para el diagnóstico se utilice la muestra de médula ósea, mientras que para los seguimientos se sugiere el uso de sangre periférica, ya que los criterios de respuesta al tratamiento están estandarizados en estas últimas muestras $[99,101]$. 
Entre otras pruebas moleculares disponibles para el análisis de alteraciones genéticas hematológicas se encuentran los microarreglos, en los que la muestra para la extracción del ADN, bien sea sangre total o médula ósea, debe ser tomada preferiblemente en tubos con heparina de sodio, de lo contrario son aceptables los tubos con EDTA [102].

\section{Otras pruebas de interés en el diagnóstico hematológico}

Adicional a las pruebas hematológicas por excelencia existen pruebas auxiliares o de otras áreas de los laboratorios clínicos que también contribuyen al diagnóstico hematológico y tienen sus propias condiciones preanalíticas respecto a la preparación del paciente, la toma, el transporte, la conservación y la centrifugación de las muestras. En la tabla 6 se resumen algunas de las pruebas que complementan el diagnóstico hematológico y las consideraciones especiales a tener presente.

\section{Conclusiones}

En el diagnóstico hematológico los exámenes de laboratorio son la principal fuente de información para la toma de decisiones médicas relacionadas con el tratamiento y el seguimiento de los pacientes. Dada la diversidad del personal involucrado en la toma de las muestras para el diagnóstico hematológico, las variaciones en la preparación del paciente requeridas para cada tipo de estudio, la heterogeneidad de las muestras y las diferentes condiciones para la preparación e identificación del paciente, la toma de la muestra, el transporte y la conservación de las mismas, los laboratorios clínicos que ofrezcan pruebas hematológicas dentro de su portafolio de servicios deben velar por el adecuado desarrollo de todos estos procesos de la fase preanalítica, independiente del tipo de muestra y del personal a cargo de su recolección, ya que como se discutió previamente es la etapa más susceptible de errores $[7,9,11,12]$.

En este sentido, los profesionales del laboratorio clínico deben desarrollar todos los procesos con altos estándares de calidad e instaurar mecanismos de control durante la fase preanalítica, de modo que se disminuyan los errores que puedan afectar la determinación o cuantificación de analitos que, a su vez, influyen en el manejo clínico de los pacientes [4]. De esta manera, resulta clave que todo el personal tenga información clara, veraz y actualizada sobre las condiciones preanalíticas de los diversos exámenes ofrecidos por cada laboratorio clínico en particular [7].

Por ejemplo, el personal que realiza la orientación del paciente previo a la toma de la muestra debe contar con la información precisa sobre los requisitos que este debe cumplir, según el examen ordenado por el médico tratante, para brindarla oportunamente al paciente y evitar posibles interferentes en la fase analítica y 


\section{Tabla 6. Condiciones preanalíticas en pruebas complementarias para} el diagnóstico hematológico

$\begin{array}{ll}\text { Prueba } & \text { Preparación del paciente } \\ & \\ \text { Eritrosedi- } & \text { Ayuno } \\ \text { mentación } & \text { Evitar inducir hemólisis durante el pro- } \\ {[73,103]} & \text { cesamiento } \\ & \text { Evitar, en la medida de lo posible, el } \\ & \text { consumo de medicamentos interferentes } \\ & \text { como: dextrán, metildopa, anticoncepti- } \\ & \text { vos orales, penicilamina, procainamida, } \\ & \text { teofilina y vitamina A, que pueden au- } \\ & \text { mentarla, así como aspirina, cortisona y } \\ & \text { quinina que pueden disminuirla }\end{array}$

Inmu- No se requiere preparación especial
nofijación
en suero

en suero

$[73,104]$

Inmunofi- Descartar la primera micción antes de la jación en recolección de la muestra

orina [73]

\section{Electrofo- $\quad$ No se requiere preparación especial resis de proteínas en suero [73] \\ Evitar, en la medida de lo posible, el con- sumo de esteroides anabólicos, andróge- nos, corticosteroides, dextrán, hormona del crecimiento, insulina, fenazopiridina y progesterona ya que pueden aumen- tar los niveles, así como de estrógenos, hepatotóxicos y anticonceptivos orales pues pueden disminuir los niveles}

\section{Consideraciones especiales para la toma de la muestra}

\section{1 tubo con EDTA} (tapa lila)

Evitar estasis venosa

1 tubo seco (tapa roja) o con gel separador (tapa amarilla) Indicar si el paciente ha recibido vacunas en los últimos seis meses

Orina de 24 horas recolectada en un recipiente de plástico con un preservante

1 tubo seco (tapa roja) o con gel separador (tapa amarilla)

Evitar la aplicación prolongada del torniquete, ya que puede aumentar las proteínas totales

Primera orina de la mañana u orina de $24 \mathrm{~h}$ en un recipiente de plástico sin preservante

[73]

\begin{tabular}{ll}
$\begin{array}{l}\text { Cadenas } \\
\text { livianas } \\
\text { libres en } \\
\text { suero } \\
\text { [105] }\end{array}$ & Ayuno \\
& \\
$\begin{array}{l}\text { Electrofo- } \\
\text { resis de } \\
\text { hemoglo- } \\
\text { bina [73] }\end{array}$ & $\begin{array}{l}\text { No se requiere preparación especial } \\
\text { te fue transfundido en las } 12 \text { semanas }\end{array}$ \\
$\begin{array}{l}\text { Eritro- } \\
\text { poyetina }\end{array}$ & $\begin{array}{l}\text { Evitar el tratamiento con ACTH, pastillas } \\
\text { anticonceptivas y esteroides previo a la }\end{array}$ \\
\hline 73$]$ & prueba pues pueden elevar los niveles
\end{tabular}

1 tubo seco (tapa roja) o con gel separador (tapa amarilla)

1 tubo con EDTA (tapa lila)

1 tubo seco (tapa roja) o con gel separador (tapa amarilla)
Conservación, transporte y centrifugación

Conservación a temperatura ambiente hasta su procesamiento

La muestra no se centrifuga Procesar antes de tres horas de recolectada la muestra

El suero se debe separar lo más rápido posible y conservar refrigerado (entre $2^{\circ} \mathrm{C}$ y $8^{\circ} \mathrm{C}$ ) por máximo una semana o congelado (-20 ${ }^{\circ} \mathrm{C}$ o menos) por máximo un mes

Conservar en hielo durante la recolección

Conservar a temperatura ambiente hasta su procesamiento por máximo 8 horas después de tomada la muestra, refrigerada entre $2{ }^{\circ} \mathrm{C}$ y 8 ${ }^{\circ} \mathrm{C}$ por una semana o congelada a $-20^{\circ} \mathrm{C}$ por máximo un mes

Conservar refrigerada hasta su procesamiento

Conservar a temperatura ambiente por máximo 2 horas, refrigerar máximo por una semana o congelar máximo por dos semanas antes de su procesamiento

La muestra se puede conservar refrigerada máximo por 7 días

Conservar a temperatura ambiente por máximo 4 horas o refrigerada por máximo un día hasta su procesamiento 
Crioglobulinas $[106,107]$

Ayuno

Evitar el consumo de drogas de abuso como la cocaína

Evitar la toma de muestra después de una vacunación

Crioaglu- Ayuno
tininas
$[108]$

$\begin{array}{ll}\text { Fragilidad } & \text { No se requiere preparación especial } \\ \text { osmótica } & \text { En la medida de lo posible, evitar la toma } \\ \text { [58] } & \text { de la muestra durante una crisis hemolítica } \\ & \text { aguda o si el paciente fue transfundido en } \\ & \text { los últimos tres a cuatro meses } \\ & \text { Evitar el consumo de dapsona previo a } \\ & \text { la prueba }\end{array}$

Coombs Evitar, en la medida de lo posible, el condirecto sumo de medicamentos como ampicilina, [73] captopril, cefalosporinas, clorpromazina clorpropamida, hidralazina, indometacina, insulina, isoniazida, levodopa, metildopa, penicilina, fenitoína, procainamida, quinidina, quinina, rifampicina, estreptomicina, sulfonamidas y tetraciclinas pues pueden inducir resultados falsos positivos

1 tubo seco (tapa roja) o con gel separador (tapa amarilla)

1 tubo seco (tapa roja) o con ge separador (tapa amarilla) precalentado a 37 El tubo debe ser exclusivo para esta prueba

1 tubo seco (tapa roja) o con gel separador (tapa amarilla) precalentado a $37^{\circ} \mathrm{C}$ El tubo debe ser exclusivo para esta prueba

1 tubo con EDTA (tapa lila)

Transportar a $37^{\circ} \mathrm{C}$ y dejar en reposo 1 hora antes de centrifugar

Conservar a esta temperatura todo el tiempo

Transportar a $37^{\circ} \mathrm{C}$ y dejar en reposo 1 hora antes de centrifugar

Conservar a esta temperatura todo el tiempo

La muestra se debe conservar a temperatura ambiente por máximo 3 días, refrigerada por una semana.

La muestra no se debe congelar

Inmediatamente después de tomar la muestra transferir a un recipiente sin anticoagulantes ni activadores de la coagulación y desfibrinar por agitación con perlas de vidrio La muestra, ya desfibrinada, se puede conservar a temperatura ambiente por máximo 24 horas antes de ser procesada

1 tubo con EDTA (tapa lila)

Mantener cerrado hasta que se vaya a procesar La muestra es estable por siete días refrigerada de 2 ${ }^{\circ} \mathrm{C}$ a $8{ }^{\circ} \mathrm{C}$ dido en los últimos tres a cuatro mese pues puede producir falsos negativos Evitar el consumo de fenotiazinas ya que inducen resultados falsos negativos

$\begin{array}{ll}\begin{array}{l}\text { Holotrans- } \\ \text { cobalami- } \\ \text { na [109] }\end{array} & \text { Ayuno } \\ & \\ \text { Homocis- } & \begin{array}{l}\text { Ayuno } \\ \text { teína [73] }\end{array} \\ & \begin{array}{l}\text { Evitar el consumo de cigarrillo previo a } \\ \text { la prueba } \\ \text { Evitar, en la medida de lo posible, el con- } \\ \text { sumo de medicamentos como azaribina, } \\ \text { carbamazepina, metotrexato, óxido ni- } \\ \text { troso, teofilina, fenitoína ya que pueden } \\ \text { aumentar los niveles, como también se } \\ \text { debe evitar el ácido fólico, los anticon- } \\ \text { ceptivos orales y el tamoxifeno debido a } \\ \text { que pueden disminuir los niveles }\end{array}\end{array}$

1 tubo seco (tapa roja) o con gel separador (tapa amarilla), previamente refrigerado

Idealmente 1 tubo con EDTA (tapa lila), previamente refrigerado

Según el método, 1 tubo con heparina (tapa verde) o citrato de sodio (tapa azul)
Transportar y centrifugar en condiciones de refrigeración Almacenar con o sin el coágulo hasta por tres días entre 2 ${ }^{\circ} \mathrm{C}$ y $8^{\circ} \mathrm{C}$

Si el análisis toma más tiempo en realizarse, retirar el suero y almacenarlo a $-20^{\circ} \mathrm{Co}$ menos por máximo seis meses

Transportar y centrifugar en condiciones de refrigeración La muestra se debe centrifugar antes de 30 minutos para evitar la liberación de la homocisteína intraeritrocitaria 


\begin{tabular}{|c|c|c|c|}
\hline $\begin{array}{l}\text { Haptoglo- } \\
\text { bina [73] }\end{array}$ & $\begin{array}{l}\text { Evitar, en la medida de lo posible, el con- } \\
\text { sumo de medicamentos como andróge- } \\
\text { nos y esteroides pues pueden aumentar } \\
\text { los niveles, como también de clorproma- } \\
\text { zina, difenhidramina, indometacina, iso- } \\
\text { niazida, nitrofurantoina, anticonceptivos } \\
\text { orales, quinidina y estreptomicina que } \\
\text { pueden disminuir los niveles }\end{array}$ & $\begin{array}{l}1 \text { tubo seco (tapa } \\
\text { roja) o con gel } \\
\text { separador (tapa } \\
\text { amarilla) } \\
\text { Evitar la hemólisis } \\
\text { inducida }\end{array}$ & $\begin{array}{l}\text { Ninguna condición especial } \\
\text { La muestra es estable a } \\
\text { condiciones de congelación } \\
\text { hasta por dos semanas }\end{array}$ \\
\hline $\begin{array}{l}\text { Otros mar- } \\
\text { cadores bio- } \\
\text { químicos: } \\
\text { bilimubina } \\
\text { total, directa } \\
\text { e indirecta, } \\
\text { ferritina, vi- } \\
\text { tamina B12, } \\
\text { ácido fólico, } \\
\text { deshidroge- } \\
\text { nasa láctica } \\
\text { [73] }\end{array}$ & $\begin{array}{l}\text { Ayuno } \\
\text { No consumir bebidas alcohólicas previo } \\
\text { a la prueba } \\
\text { Evitar el ejercicio extenuante } \\
\text { Nota: no se incluyen los medicamentos } \\
\text { que se deben evitar antes de la toma de } \\
\text { la muestra pues existe una alta variedad } \\
\text { por cada analito a estudiar }\end{array}$ & $\begin{array}{l}1 \text { tubo seco (tapa } \\
\text { roja) o con gel } \\
\text { separador (tapa } \\
\text { amarilla) } \\
\text { Evitar la hemólisis } \\
\text { inducida }\end{array}$ & $\begin{array}{l}\text { Transportar inmediatamen- } \\
\text { te al laboratorio } \\
\text { En el caso de la medición } \\
\text { de bilirrubina proteger los } \\
\text { tubos de la luz y no agitarlos } \\
\text { Nota: no se especifican las } \\
\text { condiciones de almacena- } \\
\text { miento y transporte pues } \\
\text { varían según el analito a } \\
\text { analizar }\end{array}$ \\
\hline
\end{tabular}

posanalítica. Para esto, la comunicación oportuna y la educación continua del personal encargado, como responsabilidad de los laboratorios clínicos, se convierte en una estrategia útil para la prestación de un servicio integral y de máxima calidad desde el primer momento en que el paciente tiene contacto con los servicios de los laboratorios.

Por otra parte, debido a que en la mayoría de los laboratorios clínicos y entidades hospitalarias la toma de la muestra no está a cargo de los bacteriólogos y microbiólogos, sino del personal médico y de enfermería, es importante que los laboratorios no se desliguen de este proceso y tengan un rol activo, haciéndose responsables del entrenamiento y la formación constante de todo el personal que participa en la toma de las muestras sobre las variables preanalíticas y el impacto de no cumplirlas $[7,56]$.

En el área de la hematología, algunas de las muestras más críticas son obtenidas mediante procedimientos invasivos como el aspirado y la biopsia de médula ósea y la punción lumbar. En este caso, el laboratorio debe instruir al personal de enfermería que acompaña a los médicos hematólogos y los médicos oncólogos durante la toma de la muestra sobre las condiciones propias de cada procedimiento a realizar; además de proveer la información y los recursos suficientes para garantizar la adecuada toma, transporte y conservación de estas muestras tan valiosas hasta los sitios propios de procesamiento (laboratorios de hematología, citometría de flujo, biología molecular, citogenética, entre otros).

Por lo anterior, la fase preanalítica se debe constituir en una de las prioridades de los sistemas de gestión de la calidad de los laboratorios clínicos, en cuyo caso es imprescindible la definición de las políticas de toma de muestras, el establecimiento de estrategias para la identificación de errores, la aplicación de actividades de 
mejora y el entrenamiento continuo del personal (nuevo y antiguo), en especial, cuando se trata de muestras invasivas y en las que participa personal distinto al del laboratorio, tal y como ocurre en la recolección de la mayoría de pruebas de hematopatología. El fortalecimiento del sistema de gestión de la calidad impactará positivamente en la utilidad clínica de los resultados emitidos, mejorará la confianza del personal médico ante los laboratorios y garantizará que el laboratorio avance en sus metas de calidad y cada vez busque el logro de estándares más estrictos de calidad.

\section{Bibliografía}

1. Browning RA. The Labor Shortage, Patient Safety, and Length of Stay: New Era of Change Agents Prompts Process Improvements through Lab Automation. JALA 2004; 9: 2427.

2. Suardíaz J, Cruz C, Colina A. Laboratorio Clínico. La Habana, Cuba: Editorial Ciencias Médicas; 2004.

3. Rodríguez-Ravelo MA, Abraham-Marcel E. Las variables preanalíticas y su influencia en los resultados de laboratorio clínico. Rev Mex Patol Clin 2007; 54: 159-167.

4. Carraro $\mathbf{P}, \mathbf{P l e b a n i} \mathbf{M}$. Errors in a stat laboratory: types and frequencies 10 years later. Clin Chem 2007; 53: 1338-1342.

5. Instituto Colombiano de Normas Técnicas y Certificación (ICONTEC). Laboratorios clínicos. Requisitos generales para la calidad y la competencia. Norma Técnica Colombiana NTC-ISO 15189; 2014.

6. CLSI. Quality Management System: A Model for Laboratory Services; Approved Guideline-Fourth edition. CLSI document QMS01-A4. Pensilvania, Estados Unidos: Clinical and Laboratory Standards Institute; 2011.

7. Lippi G, Banfi G, Buttarello M, Ceriotti F, Daves M, Dolci A, et al. Recommendations for detection and management of unsuitable samples in clinical laboratories. Clin Chem Lab Med 2007; 45: 728-736.

8. Kalra J. Medical errors: impact on clinical laboratories and other critical areas. Clin Biochem 2004; 37: 1052-1062.

9. Bonini P, Plebani M, Ceriotti F, Rubboli F. Errors in laboratory medicine. Clin Chem 2002; 48: 691-698.

10. Wiwanitkit $\mathbf{V}$. Types and frequency of preanalytical mistakes in the first Thai ISO 9002:1994 certified clinical laboratory, a 6 month monitoring. BMC Clin Pathol 2001; 1 : 5 .
11. Nutting PA, Main DS, Fischer PM, Stull TM, Pontious $M$, Seifert $M$, Jr., et al. Toward optimal laboratory use. Problems in laboratory testing in primary care. JAMA 1996; 275: 635-639.

12. Plebani M, Carraro P. Mistakes in a stat laboratory: types and frequency. Clin Chem 1997; 43: 1348-1351.

13. Wang $S$, Ho V. Corrections of clinical chemistry test results in a laboratory information system. Arch Pathol Lab Med 2004; 128: 890892.

14. Campuzano-Maya G. Alteraciones del hemograma relacionadas con los contadores de células. Medicina \& Laboratorio 2005; 11: 363-384.

15. Green SF. The cost of poor blood specimen quality and errors in preanalytical processes. Clin Biochem 2013; 46: 1175-1179.

16. Picossi-García S, Molina Mendoza P, Pérez Milena A, Aguilera Fuentes $C$, Espinar Parejo P, Lopera Puerto M. Cumplimiento de 12 horas de ayuno para la realización de análisis de sangre en la zona básica de salud de Archidona. Medicina de Familia (And) 2004; 5: 136-139.

17. España, Ministerio de Sanidad y Consumo, Instituto Nacional de Gestión Sanitaria. Actualización de la Fase Preanalítica de los Laboratorios Clínicos del Hospital «Cruz Roja» del INGESA de Ceuta Madrid, España. 2007. Disponible: http://www.ingesa.msssi. gob.es/estadEstudios/documPublica/pdf/actualzFasePreanalitica.pdf. Consultado: oct 2016.

18. McCay L, Lemer $C$, Wu AW. Laboratory safety and the WHO World Alliance for Patient Safety. Clin Chim Acta 2009; 404: 6-11.

19. Céspedes-Quevedo MC, Edward-Seringe S. Preparación del paciente y colección de muestras para análisis de Laboratorio Clínico. MEDISAN 1999; 3: 31-35. 
20. Laposata M, Dighe A. «Pre-pre» and «postpost» analytical error: high-incidence patient safety hazards involving the clinical laboratory. Clin Chem Lab Med 2007; 45: 712-719.

21. Wallin 0 , Soderberg $J$, Van Guelpen B, Stenlund H, Grankvist K, Brulin C. Preanalytical venous blood sampling practices demand improvement--a survey of test-request management, test-tube labelling and information search procedures. Clin Chim Acta 2008; 391: 91-97.

22. Galban G, Misino S, Wekken MVD, Tomassini L, Suarez M. Errores Pre-analíticos (EPA) en el Laboratorio de Guardia del Hospital Interzonal Especializado Materno Infantil (HIEMI) de la Ciudad de Mar del Plata. Rev Bioanálisis 2007: 18-21.

23. Lima-Oliveira G, Volanski W, Lippi G, Picheth G, Guidi GC. Pre-analytical phase management: a review of the procedures from patient preparation to laboratory analysis. Scand J Clin Lab Invest 2017; 77: 153-163.

24. Kumar-Nigam P. Preanalytical Errors: Some common errors in Blood Specimen Collection for routine investigations in hospital patients. J Clin Diagn Res 2011; 5: 659-661.

25. Stankovic AK, DiLauri E. Quality improvements in the preanalytical phase: focus on urine specimen workflow. Clin Lab Med 2008; 28: 339-350, viii.

26. Lippi G, Mattiuzzi C, Bovo C, Favaloro EJ. Managing the patient identification crisis in healthcare and laboratory medicine. Clin Biochem 2017; feb 4 [Epub ahead of print].

27. Henry JB, Kurec AS. Laboratorio clínico: organización, objetivos y práctica. En: Henry JB, ed. Henry - El Laboratorio en el Diagnóstico Clínico. Madrid, España: Marbán; 2005: 3-49.

28. Lippi G, Salvagno GL, Montagnana $M$, Lima-Oliveira G, Guidi GC, Favaloro EJ. Quality standards for sample collection in coagulation testing. Semin Thromb Hemost 2012; 38: 565-575.

29. Polack B, Schved JF, Boneu B. Preanalytical recommendations of the 'Groupe d'Etude sur I'Hemostase et la Thrombose' (GEHT) for venous blood testing in hemostasis laboratories. Haemostasis 2001; 31: 61-68.

30. Blomback M, Konkle BA, Manco-Johnson MJ, Bremme K, Hellgren M, Kaaja R. Preanalytical conditions that affect coagulation testing, including hormonal status and therapy. J Thromb Haemost 2007; 5: 855-858.

31. Favaloro EJ, Lippi G. Laboratory reporting of hemostasis assays: the final post-analytical opportunity to reduce errors of clinical diagnosis in hemostasis? Clin Chem Lab Med
2010; 48: 309-321.

32. Favaloro EJ, Bonar R, Duncan E, Earl G, Low J, Aboud M, et al. Identification of factor inhibitors by diagnostic haemostasis laboratories: a large multi-centre evaluation. Thromb Haemost 2006; 96: 73-78.

33. Samama MM, Contant G, Spiro TE, Perzborn $E$, Le Flem L, Guinet $C$, et al. Laboratory assessment of rivaroxaban: a review. Thromb J 2013; 11: 11.

34. Baglin T, Keeling D, Kitchen S. Effects on routine coagulation screens and assessment of anticoagulant intensity in patients taking oral dabigatran or rivaroxaban: guidance from the British Committee for Standards in Haematology. Br J Haematol 2012; 159: 427429.

35. Ikeda K, Tachibana H. Clinical implication of monitoring rivaroxaban and apixaban by using anti-factor $X a$ assay in patients with non-valvular atrial fibrillation. J Arrhythm 2016; 32: 42-50.

36. Mullins CA. Recolección de la muestra. En: Rodak BF, ed. Hematología: Fundamentos y Aplicaciones Clínicas (ed 2da). Buenos Aires, Argentina: Editorial Médica Panamericana; 2005: 19-32.

37. Favaloro EJ, Lippi G, Raijmakers MT, Vader HL, van der Graaf F. Discard tubes are sometimes necessary when drawing samples for hemostasis. Am J Clin Pathol 2010; 134: 851.

38. Adcock Funk DM, Lippi G, Favaloro EJ. Quality standards for sample processing, transportation, and storage in hemostasis testing. Semin Thromb Hemost 2012; 38: 576-585.

39. CLSI. Tubes and Additives for Venous and. Capillary Blood Specimen Collection; Approved Standard-Sixth Edition. CLSI document H01-A6. Pensilvania, Estados Unidos: Clinical and Laboratory Standards Institute; 2010.

40. van Balveren JA, Huijskens MJ, Gemen EF, Pequeriaux NC, Kusters R. Effects of time and temperature on 48 routine chemistry, haematology and coagulation analytes in whole blood samples. Ann Clin Biochem 2016; nov 2 [Epub ahead of print].

41. Heil W, Grunewald $R$, Amend $M$, Heins $M$. Influence of time and temperature on coagulation analytes in stored plasma. Clin Chem Lab Med 1998; 36: 459-462.

42. Bohm M, Taschner S, Kretzschmar E, GerIach R, Favaloro EJ, Scharrer I. Cold storage of citrated whole blood induces drastic time-dependent losses in factor VIII and von Willebrand factor: potential for misdiagnosis of haemophilia and von Willebrand disease. 
Blood Coagul Fibrinolysis 2006; 17: 39-45.

43. Food and Drug Administration (FDA). 510(k) Substantial equivalence determination decision summary: Sysmex America, Inc.; Sysmex ${ }^{\circledR}$ XN-Series (XN-10, XN-20) Automated Hematology Analyzers. 2016. Disponible: https://www.accessdata.fda.gov/cdrh docs/reviews/K112605.pdf. Consultado: oct 2016.

44. Dalby MC, Davidson SJ, Burman JF, Davies SW. Diurnal variation in platelet aggregation iwth the PFA-100 platelet function analyser. Platelets 2000; 11: 320-324.

45. Siemens Healthcare Diagnostics Inc. Dade ( $)$ PFA Cartucho de Prueba Colágeno/ EPI y Dade $®$ PFA Cartucho de Prueba Colágeno/ADP. Illinois, Estados Unidos. 2012.

46. Campuzano-Maya G. Resistencia a la aspirina: un problema de alto riesgo. Medicina \& Laboratorio 2016; 22: 13-54.

47. Linnemann B, Schwonberg J, Rechner AR, Mani H, Lindhoff-Last E. Assessment of clopidogrel non-response by the PFA-100 system using the new test cartridge INNOVANCE PFA P2Y. Ann Hematol 2010; 89: 597-605.

48. Tsantes A, Ikonomidis $I$, Papadakis $I$, Kottaridi C, Tsante A, Kalamara E, et al. Evaluation of the role of the new INNOVANCE PFA P2Y test cartridge in detection of clopidogrel resistance. Platelets 2012; 23: 481-489.

49. Kunicki TJ, Williams SA, Salomon $D R$, Harrison $P$, Crisler $P$, Nakagawa $P$, et al. Genetics of platelet reactivity in normal, healthy individuals. J Thromb Haemost 2009; 7: 2116-2122.

50. Campuzano-Maya G. PFA-100: una nueva prueba de función plaquetaria sustituta del tiempo de sangría. Medicina \& Laboratorio 2013; 19: 511-548.

51. Harrison $P$, Mackie $I$, Mumford A, Briggs C, Liesner R, Winter M, et al. Guidelines for the laboratory investigation of heritable disorders of platelet function. $\mathrm{Br}$ J Haematol 2011; 155: 30-44.

52. Hayward CP, Moffat KA, Raby A, Israels S, Plumhoff E, Flynn G, et al. Development of North American consensus guidelines for medical laboratories that perform and interpret platelet function testing using light transmission aggregometry. Am J Clin Pathol 2010; 134: 955-963.

53. Guevara-Arismendy NM, Escobar-Gallo GE, Campuzano-Maya G. Utilidad clínica de la agregometría plaquetaria. Medicina \& Laboratorio 2012; 18: 311-332.

54. Laboratorio Clínico Hematológico. Cofactor de ristocetina. Medicina \& Laboratorio 2014; 20: 579-584.
55. Laboratorio Clínico Hematológico. Agregación plaquetaria: ácido araquidónico. Medicina \& Laboratorio 2016; 22: 87-92.

56. Upreti S, Upreti S, Bansal R, Jeelani N, Bharat $\mathbf{V}$. Types and frequency of preanalytical errors in haematology lab. J Clin Diagn Res 2013; 7: 2491-2493.

57. HarsimranKaur VN, Selhi PK, Sood $\mathbf{N}$, Singh A. Preanalytical Errors in Hematology Laboratory- an Avoidable Incompetence. Iran J Pathol 2016; 11: 151-154.

58. Bates $I$, Lewis SM. Reference ranges and normal value. En: Bain BJ, Bates I, Laffan MA, Lewis SM, eds. Dacie and Lewis Practical Hematology (ed 11a). China: Elsevier Churchill Livingstone; 2011: 11-22.

59. Karandikar NJ, Hotchkiss EC, McKenna RW, Kroft SH. Transient stress lymphocytosis: an immunophenotypic characterization of the most common cause of newly identified adult lymphocytosis in a tertiary hospital. Am J Clin Pathol 2002; 117: 819-825.

60. Avloniti AA, Douda HT, Tokmakidis SP, Kortsaris AH, Papadopoulou EG, Spanoudakis EG. Acute effects of soccer training on white blood cell count in elite female players. Int J Sports Physiol Perform 2007; 2: 239249.

61. Lippi G, Avanzini P, Aloe R, Cervellin G. Blood collection from intravenous lines: is one drawing site better than others? Lab Med 2014; 45: 172-175.

62. Lima-Oliveira G, Guidi GC, Salvagno GL, Montagnana M, Rego FGM, Lippi G, et al. Is Phlebotomy Part of the Dark Side in the Clinical Laboratory Struggle for Quality? Laboratory Medicine 2012; 43: 172-176.

63. Vives-Corrons JL, Aguilar-Bascompte JL. Manual de técnicas de laboratorio en hematología (ed 3ra). Barcelona, España: Masson S.A.; 2006.

64. Buttarello M. Quality specification in haematology: the automated blood cell count. Clin Chim Acta 2004; 346: 45-54.

65. Narayanan S. The preanalytic phase. An important component of laboratory medicine. Am J Clin Pathol 2000; 113: 429-452.

66. Briggs $C$, Longair I, Kumar $P$, Singh $D$, Machin SJ. Performance evaluation of the Sysmex haematology XN modular system. ] Clin Pathol 2012; 65: 1024-1030.

67. Buoro S, Mecca T, Seghezzi M, Manenti B, Cerutti L, Dominoni P, et al. Assessment of blood sample stability for complete blood count using the Sysmex XN-9000 and Mindray BC-6800 analyzers. Rev Bras Hematol Hemoter 2016; 38: 225-239. 
68. Houwen B. Blood film preparation and staining procedures. Clin Lab Med 2002; 22: 1-14, v.

69. Duboscq C, Kordich L. Efecto de la concentración de citrato de sodio sobre las pruebas de hemostasia. Acta Bioquím Clín Latinoam 2005; 39: 87-92.

70. Bain BJ, Lewis SM. Preparation and staining methods for blood and bone marrow films. En: Bain BJ, Bates I, Laffan MA, Lewis SM, eds. Dacie and Lewis Practical Hematology (ed 11a). China: Elsevier Churchill Livingstone; 2011: 57-68.

71. Riley RS, Williams $D$, Ross M, Zhao S, Chesney A, Clark BD, et al. Bone marrow aspirate and biopsy: a pathologist's perspective. II. interpretation of the bone marrow aspirate and biopsy. J Clin Lab Anal 2009; 23: 259-307.

72. Riley RS, Hogan TF, Pavot DR, Forysthe R, Massey D, Smith E, et al. A pathologist's perspective on bone marrow aspiration and biopsy: I. Performing a bone marrow examination. J Clin Lab Anal 2004; 18: 70-90.

73. Pagana KD, Pagana TJ. Mosby's Manual of diagnostic and Laboratory test (ed 4a). Misuri, Estados Unidos: Mosby Elsevier; 2010.

74. Bates I, Burthem J. Bone marrow biopsy. En: Bain BJ, Bates I, Laffan MA, Lewis SM, eds. Dacie and Lewis Practical Hematology (ed 11a). China: Elsevier Churchill Livingstone; 2011: 123-137.

75. Bain BJ. Bone marrow aspiration. J Clin Pathol 2001; 54: 657-663.

76. Foucar K. Procurement and Indications for Bone Marrow Examination En: Foucar K, Reichard K, Czuchlewski D, eds. Bone Marrow Pathology. Vol. 1 (ed 3a). Chicago, Estados Unidos: ASCP Press; 2010: 53-66.

77. Bain BJ, Clark DM, Wilkins BS. Bone Marrow Pathology (ed 4a). Nueva Jersey, Estados Unidos: Wiley-Blackwell; 2010.

78. Rodolfo P. C, Ana Carolina A. B, Annelise C. W. L, Alex F. S, Ana Paula d, Marta A. V, et al. Recomendações para garantia da qualidade em citometria de fluxo multiparamétrica: primeiro consenso do Grupo Brasileiro de Citometria de Fluxo (GBCFLUX). J Bras Patol Med Lab 2015; 51: 389-396.

79. Wood BL, Arroz M, Barnett D, DiGiuseppe J, Greig B, Kussick SJ, et al. 2006 Bethesda International Consensus recommendations on the immunophenotypic analysis of hematolymphoid neoplasia by flow cytometry: optimal reagents and reporting for the flow cytometric diagnosis of hematopoietic neoplasia. Cytometry B Clin Cytom 2007; 72 Suppl 1: S14-22.
80. Davis BH, Holden JT, Bene MC, Borowitz MJ, Braylan RC, Cornfield D, et al. 2006 Bethesda International Consensus recommendations on the flow cytometric immunophenotypic analysis of hematolymphoid neoplasia: medical indications. Cytometry B Clin Cytom 2007; 72 Suppl 1: S5-13.

81. van Dongen JJ, Lhermitte $L$, Bottcher $S$, Almeida J, van der Velden VH, FloresMontero J, et al. EuroFlow antibody panels for standardized n-dimensional flow cytometric immunophenotyping of normal, reactive and malignant leukocytes. Leukemia 2012; 26: 1908-1975.

82. Karnes HE, Frater JL. A quality improvement assessment of multiple, concurrent flow cytometry analyses at a tertiary care center. Int J Lab Hematol 2015; 37: 90-97.

83. Stetler-Stevenson M, Yuan CM. Flow Cytometry. En: Jaffe ES, Harris NL, Vardiman JW, Campo E, Arber DA, eds. Hematopathology (ed 1a). China: Saunders-Elsevier; 2011: 4655.

84. Heins M. Quality control in the preanalytical phase of flow cytometry. Infusionsther Transfusionsmed 1996; 23: 107-108.

85. Bene MC, European LeukemiaNet. ELN - WP10 - Consensual recommendations on preanalytical precautions for the immunophenotyping of leukemia and immunoproliferative disorders. 2005. Disponible: https:// www.leukemia-net.org/content/diagnostics/ diagnostics/documents/e5821/infoboxContent5823/WP10preanayticall.pdf. Consultado: oct 2016.

86. Borowitz MJ, Craig FE, Digiuseppe JA, Illingworth AJ, Rosse W, Sutherland DR, et al. Guidelines for the diagnosis and monitoring of paroxysmal nocturnal hemoglobinuria and related disorders by flow cytometry. Cytometry B Clin Cytom 2010; 78: 211-230.

87. Reichard K. Specialized Techniques in Bone Marrow Evaluation En: Foucar K, Reichard K, Czuchlewski D, eds. Bone Marrow Pathology. Vol. 1 (ed 3a). Chicago, Estados Unidos: ASCP Press; 2010: 67-84.

88. Mayall F, Darlington A, Harrison B. Fine needle aspiration cytology in the diagnosis of uncommon types of lymphoma. J Clin Pathol 2003; 56: 821-825.

89. Biesemier KW, Dent GA, Pryzwansky KB, Folds JD. A comparative study of frozensection immunoperoxidase and flow cytometry for immunophenotypic analysis of lymph node biopsies. Clin Diagn Lab Immunol 1994; 1: 299-303.

90. Ruiz-Arguelles A, Rivadeneyra-Espinoza L, Duque RE, Orfao A. Report on the second Latin American consensus conference for flow 
cytometric immunophenotyping of hematological malignancies. Cytometry B Clin Cytom 2006; 70: 39-44.

91. Keagle MB. Quality Control and Quality Assurance. En: Gersen SL, Keagle MB, eds. The Principles of Clinical Cytogenetics (ed 3a). Nueva York, Estados Unidos: Springer; 2013: 77-94.

92. Micale MA. Classical and Molecular Cytogenetic Analysis of Hematolymphoid Disorders. En: Crisan D, ed. Hematopathology: Genomic Mechanisms of Neoplastic Diseases. Nueva York, Estados Unidos: Humana Press; 2010: 39-78.

93. Keagle MB, Gersen SL. Basic Cytogenetics Laboratory Procedures. En: Gersen SL, Keagle MB, eds. The Principles of Clinical Cytogenetics (ed 3a). Nueva York, Estados Unidos: Springer; 2013: 53-65.

94. Vulliamy T, Kaeda J, Foroni L, Bain BJ. Molecular and cytogenetic analysis. En: Bain B], Bates I, Laffan MA, Lewis SM, eds. Dacie and Lewis Practical Hematology (ed 11a). China: Elsevier Churchill Livingstone; 2011: 139-174.

95. Bulla LMC, Ambrosio EP, Martins ABT, DellaRosa VA. Viability of lymphocyte culture, at different times after blood collection, for karyotype analysis. Jornal Brasileiro de Patologia e Medicina Laboratorial 2014; 50: 124-130.

96. Morrissette JJD, Weck K, Dunphy $\mathbf{C H}$, Techniques to Detect Defining Chromosomal Translocations/Abnormalities. En: Dunphy $\mathrm{CH}$, ed. Molecular Pathology of Hematolymphoid Diseases. Nueva York, Estados Unidos: Springer; 2010: 129-152.

97. Barroca H, Marques C. A Basic Approach to Lymph Node and Flow Cytometry Fine-Needle Cytology. Acta Cytol 2016; 60: 284-301.

98. Boyanton BLJ, Rushton JR. Molecular Techniques in Hematopathology. En: Crisan D, ed. Hematopathology: Genomic Mechanisms of Neoplastic Diseases. Nueva York, Estados Unidos: Humana Press; 2010: 1-38.

99. Payne DA, Baluchova K, Peoc'h KH, van
Schaik RH, Chan KC, Maekawa M, et al. Pre-examination factors affecting molecular diagnostic test results and interpretation: A case-based approach. Clin Chim Acta 2016.

100. CLSI. Collection, Transport, Preparation, and Storage of Specimens for Molecular Methods; Approved Guideline. CLSI document MM13-A. Pensilvania, Estados Unidos: Clinical and Laboratory Standards Institute; 2005.

101. Jabbour E, Kantarjian H. Chronic myeloid leukemia: 2016 update on diagnosis, therapy, and monitoring. Am J Hematol 2016; 91: 252-265.

102. Mayo Medical Laboratories. Chromosomal Microarray, Hematologic Disorders. 2016. Disponible: http://www.mayomedicallaboratories.com/test-catalog/ Specimen/35899. Consultado: oct 2016.

103. Osei-Bimpong A, Burthem J. Supplementary techniques including blood parasite diagnosis. En: Bain BJ, Bates I, Laffan MA, Lewis SM, eds. Dacie and Lewis Practical Hematology (ed 11a). China: Elsevier Churchill Livingstone; 2011: 101-121.

104. Sebia. HYDRAGEL IF K20 Ref. 3031. 2011. Disponible: http://www.bganalizadores.com.ar/img/3031.pdf. Consultado: oct 2016.

105. Jenner E. Serum free light chains in clinical laboratory diagnostics. Clin Chim Acta 2014; 427: 15-20.

106. Damoiseaux J. The diagnosis and classification of the cryoglobulinemic syndrome. Autoimmun Rev 2014; 13: 359-362.

107. Ramos-Casals M, Stone JH, Cid MC, Bosch X. The cryoglobulinaemias. Lancet 2012; 379: 348-360

108. Jury C, Nagai Y, Tatsumi N. Collection and handling of blood. En: Bain BJ, Bates I, Laffan MA, Lewis SM, eds. Dacie and Lewis Practical Hematology (ed 11a). China: Elsevier Churchill Livingstone; 2011: 1-9.

109. Abbott Laboratories. ARCHITECT ACtive-B12 (Holotranscobalamin). Wiesbaden, Alemania. 2013. 